\title{
Air quality and relative humidity in commercial aircrafts: An experimental investigation on short-haul domestic flights
}

\author{
Carlo Giaconia, Aldo Orioli*, Alessandra Di Gangi \\ D.E.I.M. Dipartimento di Energia, Ingegneria dell'Informazione e Modelli Matematici, Università degli Studi di Palermo, Viale delle Scienze Edificio 9, 90128 \\ Palermo, Italy
}

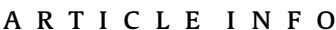

\section{Article history:}

Received 18 March 2013

Received in revised form

6 May 2013

Accepted 8 May 2013

\section{Keywords:}

Aircraft cabins

Cabin comfort

Aircraft ECS

Hygrometrical control

Air quality

Carbon dioxide

\begin{abstract}
A B S T R A C T
Nowadays the achievement of a comfortable environment in aircraft cabins is a factor of paramount importance in air travel business competition; on the other hand, the need of reducing the propulsion fuel cost has driven the airline companies to adopt air handling systems that may reduce the levels of thermal comfort and air quality inside the cabins of commercial airliners. With the aim of contributing to a better knowledge of this matter, this paper reports the results of an experimental study upon the indoor air quality aboard commercial aircrafts for 14 domestic flights less than $1 \mathrm{~h}$ and half long. The parameters monitored were temperature, relative humidity and carbon dioxide concentration; the measurements were performed during the whole flight from the take-off to the landing.

The relative humidity inside the cabin was also calculated using the rates of outside air and the carbon dioxide as a ventilation tracer; the theoretical results were compared with the measured data. The relationship between relative humidity and carbon dioxide concentration during fights was highlighted in order to define the environmental conditions that may provide acceptable levels of both the air quality and hygrometric comfort to the crew and passengers. The results of calculations confirmed the possibility of improving the hygrometric conditions in aircraft cabins without the need of using humidification systems.
\end{abstract}

(C) 2013 Elsevier Ltd. All rights reserved.

\section{Introduction}

The assessment of the air quality in commercial airliners is still an open problem that requires further investigation owing to the continuously increasing number of people that use airplanes to travel. Aircraft cabins are crowded places where the passengers have to seat for long and the lack of room and the high occupant density make people feel cramped and uncomfortable and put them at the risk of health problems. The inhalation of recirculated air can increase the probability of infection due to the spread of microbiological contaminants all around the cabin. Irritants and allergens, which are dispersed through air movements, can affect respiratory health and exacerbate chronic conditions. The concentrations of gaseous contaminants, due to the metabolic processes or to the combustion of the engine fuel, may surpass the tolerable levels. The changes in the air pressure inside the airplane during take-offs and landings can involve middle ear and paranasal sinus problems, often accompanied by dental pains.

\footnotetext{
* Corresponding author. Tel.: +39 09123861914/905; fax: +39 091484425.

E-mail address: orioli@dream.unipa.it (A. Orioli).
}

Since the 1970s, airliners are flying at an altitude of about $12,000 \mathrm{~m}$ in order to reduce the propulsion fuel cost; at these heights the environmental conditions do not allow human organism to survive and the environmental control system (ECS) of the aircraft has to provide at the same time the air supply, thermal control and cabin pressurization for the crew and passengers. In order to achieve the required cabin ventilation, the outside air is bled from a compressor stage of the gas turbine engines, upstream of the combustor. Because the temperature and pressure of this air are not suited to be delivered to the cabin, the bled air is adequately cooled and expanded before to be mixed with the recirculated air. The energy cost of providing adequate outside air for ventilation generally tends to increase with the altitude.

The assessment of the air quality has been faced following experimental approaches based both on simulated and real flights. Dechow et al. [1] used the cabins of Airbus A310 and A340 aircrafts to measure the particulate matter, the microbiological contamination and the concentration of volatile organic compounds during medium-distance and long-distance flights. A total number of 8 sensors were installed aboard the aircraft for about one year. Compared to the usual indoor atmospheres, the obtained results did not indicate more relevance to health risks or comfort restriction. 
Indoor air quality inside the cabins of Boeing 747-400, Airbus A330 and Airbus 340 aircrafts was investigated by Lee et al. [2] for 16 flights, during which the level of $\mathrm{CO}_{2}$ and the air temperature and relative humidity were measured every $5 \mathrm{~min}$. The measured carbon dioxide concentrations were below the limit set by FAA standard but exceeded the ASHRAE standard 62-1989 of $1000 \mathrm{ppm}$, ranging from 2000 to $2500 \mathrm{ppm}$. The air was quite dry, with a relative humidity varying in the range of $4.9 \%-76.8 \%$ with a temporal variation dominated by a gradual decrease during the beginning and an increase at the end of the trip. The temperature on the aircraft ranged from $19.3^{\circ} \mathrm{C}$ to $27.1^{\circ} \mathrm{C}$. Cabin crew, which completed 185 questionnaires, rated the overall air quality in the surveyed flights to be acceptable (36\%) and adequate (32\%), while the air quality was considered poor by $21 \%$ of the crew. The symptoms that were more frequently experienced during flights, whose durations ranged from $1 \mathrm{~h}$ and $25 \mathrm{~min}$ to $14 \mathrm{~h}$ and $15 \mathrm{~min}$, were dry itchy or irritated eyes, dry or stuffy nose, skin dryness or irritation and too hot or too cold air temperature.

Haghighat et al. [3] measured the temperature, relative humidity and carbon dioxide concentration aboard 43 flights on commercial airlines with duration of more than $1 \mathrm{~h}$. The data, which were collected on DC9, Boeing 767 and Airbus A320 and A340 aircrafts, were compared with the ASHRAE standards for thermal comfort and indoor air quality. The comparison showed that the air temperature was often below the recommended range and the humidity was always too low. The average values of temperature and humidity ranged between $20.2^{\circ} \mathrm{C}$ and $23.8^{\circ} \mathrm{C}$ and $1.8 \%$ and $18.5 \%$, respectively. The levels of relative humidity were very low for all flights and did not meet the lower limit of thermal comfort in ASHRAE standard 55-92. The relative humidity in the DC9, which used $100 \%$ fresh air, was higher than in the other newer aircraft models. Carbon dioxide concentration was used as the indicator of the ventilation performance and indoor air quality. $\mathrm{ACO}_{2}$ level of 1000 ppm was exceeded in 13 out of 22 flights for Airbus flights, 11 out of 15 DC9 flights and 1 out of 5 for Boeing 767 flights. Because passengers produce the carbon dioxide, it would be expected that, the fewer of them on board, it would result in better air quality. Probably, as the recirculation rate is usually controlled by the pilot and crew, who are mainly concerned with energy saving rather than passenger comfort, the air quality levels was not significantly affected by the number of passengers.

In order to evaluate the ventilation effectiveness and characterize the air distribution, Wang et al. [4] used a full-scale section of a Boeing 767 aircraft cabin containing 35 manikins, which were equipped with body heaters and outlets of $\mathrm{CO}_{2}$ to simulate breathing. Carbon dioxide was used as the tracer gas to determine the local mean age of the air and the ventilation effectiveness factor. Forced and mixed convection in a replica of a section of the Airbus A380 upper deck was experimentally investigated by Kühn et al. [5]. Large scale particle image velocimetry and temperature field measurements were conducted in a cross sectional plane of the cabin mock-up.

The results of monitoring the ozone in the cabin on a representative number of flights and aircraft, the pesticide exposure of passengers and crew, the cabin air pressure and altitude, the incidents of air contamination and the residue from aircraft ventilation ducts and filters were described in the report to the FAA issued by the Airliner Cabin Environmental Research (ACER) Program [6]. Ozone levels were measured during 68 flights domestic. Measurements of pesticides were made on 15 domestic flights and 46 international flights. In order to monitor air contamination incidents, a simple, small portable sampling device was developed and used on nearly 200 flights. The concentrations of carbon dioxide ranged between 900 and 1700 ppm, with only occasional measurements registering higher values. On most of the flights, the cabin temperature ranged from $22{ }^{\circ} \mathrm{C}$ to $29^{\circ} \mathrm{C}$ and the humidity data demonstrated a trend of starting at around 35-50\% relative humidity at the beginning of the flight and dropping to around 10$25 \%$ as the flight progressed. Moreover, about 3700 flight attendants, selected in order to get a representative distribution of flight attendant characteristics, were queried about their symptoms, diagnoses, care seeking, treatment and work-related injuries. The answers related to respiratory and visual symptoms, which can be connected to the air dryness, showed the presence of eye irritation (10.8\%), blurred vision (7.5\%), sinus congestion (29.0\%), nose irritation $(5.0 \%)$, sore throat (7.0\%), cough (10.8\%) and hoarseness (5.1\%), suffered for more than 5-6 days a week.

The ACER Center [7] also conducted an environmental monitoring in the passenger cabin of 83 commercial flights on six aircraft models (2 Airbus and 4 Boeing), flying U.S. domestic and international routes. Environmental conditions and air quality, including carbon monoxide, carbon dioxide, particles, ozone, VOCs, semi-VOCs, carbonyls, and tricresyl phosphate were monitored. Except for low pressure, occasionally high ozone, extremely dry air and perhaps slightly higher noise levels, the air quality and environmental conditions in the passenger cabin of commercial airplanes were found to be comparable or better than conditions reported for offices, schools and residences, with a few exceptions. Ventilation rates on highpassenger load flights were found to be below the required $3.5 \mathrm{~L} / \mathrm{s}$ / person, as indicated by higher carbon dioxide levels.

Gladyszewska-Fiedoruk [8] measured the carbon dioxide concentration and the values of air temperature, relative humidity and pressure during a 200 min long flight of an airliner with 150 passengers on board. The carbon dioxide concentration exceeded the recommended standards of the World Health Organisation and the pressure in cabin was half the permissible value recommended by the FAA standard. The high air temperature found and the long exposition to low values of relative humidity were considered sufficient to induce early skin degeneration and concentration problems in pilots and attendants who fly regularly.

Airborne disease transmission in airliner cabins has always been a topic of wide interest. Chen et al. [9] found that the bulk airflow pattern in the cabin played the most important role on the transport of the expiratory droplets. Further experimental and computational fluid dynamics (CFD) investigations revealed that in-flight movement of passengers and crew had a significant impact on infectious disease transmission. Transport of contaminants and particles in enclosed environments, such as aircraft cabins, has been the object of many studies [10-14]. In order to provide a healthy and comfortable environment for passengers and crew, Zhang et al. [15] studied a novel under-floor displacement air distribution system, matched with a personalized air distribution system, able to reduce the spread of infectious airborne diseases.

Possou et al. [16] and Muzumdar et al. [17] used validated CFD and a small-scale water model to assess the impact of scaling and body movement on contaminant transport in airliner cabins. Gupta et al. $[18,19]$ developed a method to predict the amount of expiratory droplets inhaled by the passengers in an airliner cabin for any flight duration; the method was used to determine the amount of droplets inhaled by the susceptible passengers over a 4-h flight, under three common scenarios. They also computed the transport of the droplets exhaled by the index patient seated in the middle of a seven-row, twin-aisle, fully-occupied cabin using CFD simulations. Gupta et al. [20] presented a comprehensive approach to assessing the spatial and temporal distribution of airborne infection risk in an aircraft cabin. Deterministic and probabilistic approaches were used to quantify the risks based on the amount of inhaled influenza virus. The study carried by Chen et al. [9] also showed that influenza survival on stainless steel surfaces are impacted by relative humidity. 
It is known that low levels of relative humidity in airplanes are usually considered advisable in order to reduce the risk of corrosion of structural elements, electrical malfunction and degradation of insulating, due to condensate, and prevent the growth of microorganisms. For this reason, and to prevent ice from forming and clogging the system, air bled from the gas turbine engine is also sent through a water separator even if, at cruise altitudes, the outside air contains very little moisture. Because the main sources of humidity in the cabin are respiration and evaporation from the skin of occupants, the relative humidity in the cabin usually reaches values of $10-20 \%$ that can affect the comfort of the occupants.

Many authors have investigated the effects of the low levels of relative humidity, which meanly are dry nose, eyes, throat and skin, by questioning the crew members and passengers [21-24]. Nagda and Hodgson [25] pointed out that some subjects were not always able to perceive low humidity or changes in the humidity level and that the perception of humidity did not vary with the duration of exposure. Moreover, it was observed that the complaints of dryness decreased by lowering the air temperature with a constant relative humidity; adversely, the perceived staleness of air increased and the perceived acceptability of air decreased with a rise in either the air temperature or humidity. The effect of humidifying the air cabin was investigated by Lindgren et al. [26] on eight intercontinental flights with a Boeing 767 aircraft.

Using realistic pollution sources, Strøm-Tejsen et al. [27] performed measurements in a simulated section of an aircraft cabin with 21 seats installed in a climatic chamber capable of providing fresh outside air at very low humidity. Experiments, which simulated 7-h transatlantic flights, were carried out at four supply rates of outside air $(1.4,3.3,4.7$ and $9.4 \mathrm{~L} / \mathrm{s}$ per person $)$ and yielded average relative humidity levels of $28 \%, 16 \%$ and $11 \%$, respectively. A total of 68 subjects filled in questionnaires, but no significant differences of symptoms were found between the four conditions, except that the reduced outside air flow intensified other complaint commonly associated with air travel (headache, dizziness and claustrophobia).

Using a $30 \mathrm{~m}$ long pressure vessel holding the first $16 \mathrm{~m}$ of a complete wide-body A310-200 aircraft and adequately controlling the air pressure, air and fuselage temperature, relative humidity, ventilation rate, noise and vibration, Grün et al. [28] analyzed the impact of low humidity levels on the human well-being during $7 \mathrm{~h}$ long-haul simulated flights. Questionnaires were filled in by 40 subjects who experienced relative humidity, varying between $10 \%$ and $40 \%$ at a temperature range of $21^{\circ} \mathrm{C}-25^{\circ} \mathrm{C}$, and atmospheric pressure between $753 \mathrm{hPa}$ and ambient conditions. Even if it was observed a trend of decreasing dissatisfaction with increasing the relative humidity, the study confirmed the evidence of the difficulty of relating the perceived dryness to the relative humidity. Moreover, at very low levels of relative humidity around $10 \%$, the subjects showed a significant decrease in the perception of dryness between 90 and 240 min after start of exposure.

To increase the hygrometric comfort the cabin air should be theoretically humidified to suited values. Unfortunately, humidification implies many problems that include the biological growth, which is often associated with humidifiers, the maintenance requirements of the humidification system and the weight penalty due to the water necessary to make the humidifier work. Moreover, it is sensible to minimize the risks related to structural elements corrosion and electrical malfunction. For this reason cabin humidification systems are normally not included on aircrafts.

In order to avoid too low values of the humidity when an airliner is flying at cruise altitudes, the flow rate of outside air may be reduced. Actually, there is an inherent conflict between air quality and humidity. A reduction of the flow of outside air increases the relative humidity, but also the concentration of contaminants will increase. On the other hand, in order to control the level of contaminants, it is necessary to use appropriate flows of outside air.

With the aim of contributing to a better knowledge of the topic, in this paper it is presented the experimental study of the air quality that was carried out on domestic flights linking some Italian cities. The air temperature, relative humidity and the $\mathrm{CO}_{2}$ concentration data inside the cabin of an Airbus A319 aircraft were collected in order to test the air quality and the effectiveness of the ventilation system. The relative humidity inside the cabin from take-off to touchdown was calculated using the rates of outside air evaluated using carbon dioxide as a ventilation tracer and compared with the measured data. The relationship between relative humidity and carbon dioxide concentration during fights was highlighted in order to define the environmental conditions that may provide acceptable levels of both air quality and hygrometric comfort to the crew and passengers.

\section{Experimental assessment of the air quality and relative humidity}

The experimental assessment of the air quality was performed by measuring the concentration of $\mathrm{CO}_{2}$ in the cabin. It is known that carbon dioxide, which is produced by human breathing, is not considered to be a toxic air contaminant, but it can be an asphyxiant in confined spaces. The rate at which carbon dioxide is produced depends on the diet and the physical activity. With a normal diet mix of fat, carbohydrate and protein, the $\mathrm{CO}_{2}$ generation is $310 \mathrm{~mL} / \mathrm{min}$ for an activity level of 1.2 met units [29].

Some studies [30-32] have shown that, if a ventilation rate of $7.5 \mathrm{~L} / \mathrm{s}$ per person is provided, odours of human bio-effluents from sedentary persons can kept to levels that satisfy about $80 \%$ of unadapted visitors to a space. The steady-state $\mathrm{CO}_{2}$ concentration,

Table 1

Data of flights.

\begin{tabular}{|c|c|c|c|c|c|c|c|c|}
\hline Flight no. & Air route & Passengers & Distance [km] & Altitude [m] & Date & Take-off & Landing & Duration \\
\hline 1 & Palermo-Verona & 140 & 818 & 11,278 & 08 Sep. 2011 & $08: 34$ & 09:57 & $1: 23$ \\
\hline 2 & Verona-Palermo & 70 & 818 & 11,278 & 08 Sep. 2011 & $10: 45$ & $11: 52$ & $1: 07$ \\
\hline 3 & Palermo-Verona & 143 & 818 & 11,278 & 12 Sep. 2011 & $07: 23$ & $08: 40$ & $1: 17$ \\
\hline 4 & Verona-Palermo & 113 & 818 & 11,278 & 12 Sep. 2011 & $09: 27$ & $10: 37$ & 1:09 \\
\hline 5 & Palermo-Milan & 146 & 887 & 11,278 & 12 Sep. 2011 & $12: 15$ & $13: 32$ & $1: 17$ \\
\hline 6 & Milan-Palermo & 134 & 887 & 11,278 & 12 Sep. 2011 & $14: 37$ & $15: 57$ & $1: 20$ \\
\hline 7 & Palermo-Rome & 87 & 426 & 9754 & 08 Oct. 2011 & $14: 59$ & $15: 47$ & $0: 48$ \\
\hline 8 & Rome-Palermo & 95 & 426 & 9754 & 08 Oct. 2011 & $17: 11$ & $17: 50$ & $0: 39$ \\
\hline 9 & Palermo-Turin & 81 & 905 & 10,680 & 08 Oct. 2011 & $18: 49$ & $20: 15$ & $1: 26$ \\
\hline 10 & Turin-Palermo & 84 & 905 & 10,680 & 08 Oct. 2011 & $21: 05$ & $22: 12$ & $1: 07$ \\
\hline 11 & Palermo-Rome & 107 & 426 & 9754 & 10 Oct. 2011 & $15: 12$ & $16: 01$ & $0: 49$ \\
\hline 12 & Rome-Palermo & 74 & 426 & 9754 & 10 Oct. 2011 & $17: 16$ & $17: 53$ & $0: 37$ \\
\hline 13 & Palermo-Rome & 102 & 426 & 9754 & 10 Oct. 2011 & $19: 55$ & $20: 45$ & $0: 50$ \\
\hline 14 & Rome-Palermo & 80 & 426 & 9754 & 10 Oct. 2011 & $22: 26$ & 23:03 & $0: 37$ \\
\hline
\end{tabular}


calculated with a generation of $310 \mathrm{~mL} / \mathrm{min}$ per person, will be about 700 ppmv higher than the carbon dioxide concentration in the ventilation air. Because $\mathrm{CO}_{2}$ concentrations in acceptable outdoor air typically range from 350 to 500 ppmv, a level of 10001200 ppmv has been suggested as being representative of delivery rates of $7.5 \mathrm{~L} / \mathrm{s}$ per person of outside air, when carbon dioxide is measured at equilibrium concentrations.

The experimental assessment reported in this paper was conducted in the passenger cabin of an Airbus A319 during the 14 short-haul domestic flights listed in Table 1 [33].

To monitor air quality and environmental parameters in an airliner cabin it is necessary to place sensors, which are often bulky and expensive. The study of the optimal sensor placement was faced by Zhang et al. [34] and Mazumdar et al. [35] who showed that the best location for a sensor is in the middle of the ceiling even if, to effectively detect contaminants, multipoint sampling systems for each row should be used because they can reduce the number of sensors required in the cabin. Moreover, also the practicality of using wireless sensors in airliner cabins was verified [36].

In the present study, air temperature and relative humidity measurements were performed by means of DS1923 iButton ${ }^{\circledR}$ devices, which are temperature and humidity wireless micro data loggers produced by Dallas Semiconductors. The data were sampled every minute from boarding to disembarking. With the aim of verifying the uniformity of the environmental conditions in the cabin, the air temperature and the relative humidity were measured at same time in 15 points that were regularly distributed throughout the airplane in order to divide the cabin in five sections with about the same volume, as it is shown in Fig. 1.

The temperature/humidity sensors were placed in the middle of the ceiling and in the upper part of the walls of the cabin, as it is shown in Figs. 2 and 3.

The $\mathrm{CO}_{2}$ concentrations were measured every 5 min by means of an LSI-Lastem BSO 103 probe connected to a BABUC/M portable equipment located in the middle of the cabin. The measured values of carbon dioxide concentrations were used to calculate the rate of outside air provided to the cabin during flights. Calculations were performed supposing the steady-state conditions, by means of the following equation $[29,37]$ :

$V_{0}=\frac{N_{\mathrm{CO}_{2}}}{C_{\mathrm{S}, \mathrm{CO}_{2}}-C_{0, \mathrm{CO}_{2}}} 10^{6}$

where $V_{0}=$ outside airflow rate per person [L/s]; $N_{\mathrm{CO}_{2}}=\mathrm{CO}_{2}$ generation rate per person $[\mathrm{L} / \mathrm{s}] ; \mathrm{C}_{\mathrm{S}, \mathrm{CO}_{2}}=\mathrm{CO}_{2}$ concentration in the cabin [ppmv]; $\mathrm{C}_{0, \mathrm{CO}_{2}}=\mathrm{CO}_{2}$ concentration in the outside air [ppmv].

As it has been investigated by many authors [38-41], the concentration of $\mathrm{CO}_{2}$ in the atmosphere averagely ranges from 365 to 390 ppmv; a value of 380 ppmv was used to evaluate $V_{0}$ with Eq. (1). For the carbon dioxide generation rate, a value of $310 \mathrm{~mL} / \mathrm{min}$ per person was used. The measured $\mathrm{CO}_{2}$ concentrations, the

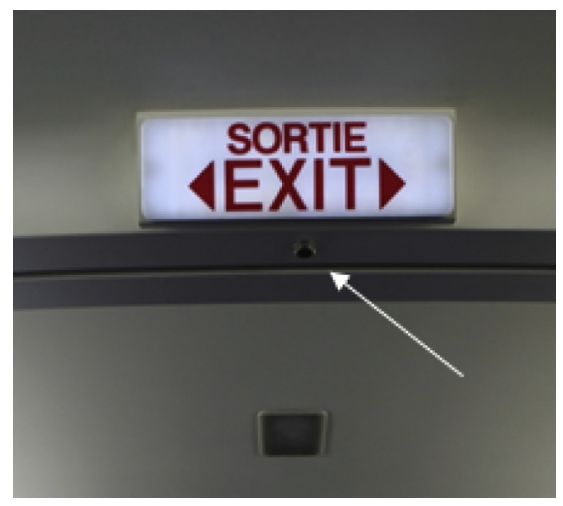

Fig. 2. Position of a temperature/humidity sensor in the ceiling of the cabin.

corresponding outside airflow rates calculated with Eq. (1) and the measured values of the relative humidity are listed in Table 2.

The concentrations of $\mathrm{CO}_{2}$ varied between 734 and $2252 \mathrm{ppm}$, which correspond to outside airflows of 14.60 and $2.76 \mathrm{~L} / \mathrm{s}$ per person, respectively. The relative humidity ranged from the very low value of $8.7 \%$, to $59.2 \%$. The greatest values of the relative humidity were reached in correspondence of take-offs. At cruise altitudes, which the airliners keep for the most part of the time, the values of relative humidity were close to the minimum values. The average relative humidity ranged from $17.9 \%$ to $27.0 \%$.

Many Authorities have set guidelines and standards for the ECSs of aircrafts. The Federal Aviation Administration, which operates in the U.S.A., and the European Joint Aviation Authorities have established design regulation FAR/JAR Part 25 that states that each crew member must have a minimum of $4.7 \mathrm{~L} / \mathrm{s}$ of fresh air to perform their duties without undue stress or discomfort. FAR Amendment No. 25-87 sets that under normal operating conditions the ventilation system must be designed to provide each occupant with airflow containing at least $0.25 \mathrm{~kg}$ of fresh air per minute, which is about $5 \mathrm{~L} / \mathrm{s}$ at $2400 \mathrm{~m}$.

Hocking [42] analyzed the problem of the aircraft cabin air quality considering trends, effects and corporate costs and made some suggestions aimed to improve passenger comfort. As it is reported by this author, coinciding with the escalation of oil prices in 1974, the rate of outside air provided per person, which was $7 \mathrm{~L} / \mathrm{s}$ since 1970 , began to be gradually reduced up to $2.8 \mathrm{~L} / \mathrm{s}$, which is the value nowadays provided by some commercial aircraft. Hocking calculated that with $1000 \mathrm{~L}$ of space per person, which is a typical value for a fully loaded aircraft, and without any air change it would take only $2.3 \mathrm{~min}$ for the concentration of $\mathrm{CO}_{2}$ to exceed the 1000 ppmv comfort upper limit recommended by ASHRAE [29]. In the opinion of this author it would have been necessary to provide to passengers an outside air ventilation rate close to the $7-9.4 \mathrm{~L} / \mathrm{s}$ per person, which are the levels provided in good current building

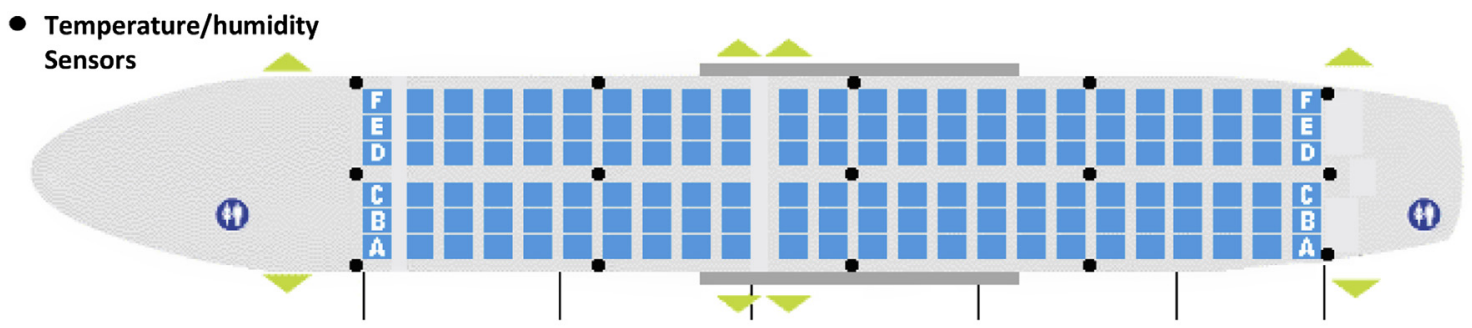

Airbuss A 319

Fig. 1. Position of the temperature/humidity sensors in the cabin. 


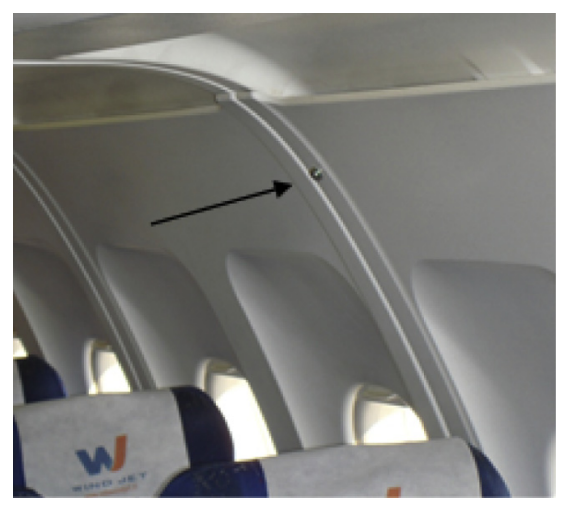

Fig. 3. Position of a temperature/humidity sensor in the wall of the cabin.

ventilation practise. Such ventilation rates should reduce the risk of transmission of airborne diseases and limit the possible discomfort effects connected to the presence of much higher than normal carbon dioxide concentrations in conjunction with the lower oxygen partial pressure, which is common at cruising altitudes. Unfortunately, as it is shown in Table 2, because no humidification is usually performed by ECSs, when very high flow rates of outside air are provided, very low levels of relative humidity in the cabin are achieved.

\section{Assessment of the expected relative humidity in the cabin}

In order to investigate the possibility of improving the hygrometric conditions in the cabin by means of a suitable reduction of the outside airflow rate, the following procedure was used. Water vapour concentration in the cabin was calculated by means of Eq. (1), which is valid in steady-state conditions:

$C_{C, \mathrm{H}_{2} \mathrm{O}}=\frac{N_{\mathrm{H}_{2} \mathrm{O}}}{V_{0}} 10^{6}+C_{0, \mathrm{H}_{2} \mathrm{O}}$

where $C_{\mathrm{C}, \mathrm{H}_{2} \mathrm{O}}=$ water vapour concentration in the cabin [ppmv]; $N_{\mathrm{H}_{2} \mathrm{O}}=$ water vapour generation rate per person [L/s]; $V_{0}=$ outside airflow rate per person [L/s]; $C_{0, \mathrm{H}_{2} \mathrm{O}}=$ water vapour concentration in the outside air [ppmv].

The water vapour generated by a person depends on the thermal comfort, or discomfort, conditions; thermal comfort corresponds to the situation in which the net difference between the total metabolic rate within the body and the rate of accomplished mechanical work is equal to heat dissipated from the body to the immediate surroundings. If this thermal equilibrium is achieved, it is possible to keep the optimal internal temperature of the body. To reach this goal, the human thermoregulation system activates many complex mechanisms, such as vasoconstriction of skin blood vessels and shivering in cold environments, and vasodilatation and sweeting in hot environments. The human body dissipates latent heat by evaporation from skin, natural diffusion of water through the skin and vapour loss from the respiratory tract to the inhaled air during respiration.

The rate of evaporative heat loss of the body is traditionally described with the following relations [43-46]:

$E=E_{\mathrm{rsw}}+E_{\mathrm{dif}}+E_{\mathrm{res}}$

with:

$E_{\mathrm{rsw}}=0.42(M-W-58.15)$

$E_{\mathrm{dif}}=3.05\left[5.73-0.007(M-W)-p_{\mathrm{v}}\right]$

$E_{\text {res }}=0.0173 M\left(5.87-p_{\mathrm{v}}\right)$

where $E_{\mathrm{rsw}}=$ rate of heat loss due to sweating $\left[\mathrm{W} / \mathrm{m}^{2}\right] ; E_{\mathrm{dif}}=$ rate of heat loss due to water diffusion through the skin $\left[\mathrm{W} / \mathrm{m}^{2}\right] ; E_{\text {res }}=$ rate of heat loss due to respiration $\left[\mathrm{W} / \mathrm{m}^{2}\right] ; M=$ rate of metabolic heat production $\left[\mathrm{W} / \mathrm{m}^{2}\right] ; W=$ rate of mechanical work accomplished $\left[\mathrm{W} / \mathrm{m}^{2}\right] ; p_{\mathrm{v}}=$ vapour pressure in the cabin $[\mathrm{kPa}]$.

The water vapour generation rate per person can be calculated considering the body surface area of a person and the thermal energy that is necessary to transform the liquid water, or sweat, into vapour:

$M_{\mathrm{H}_{2} \mathrm{O}}=\frac{E S_{\mathrm{b}}}{\Delta h}$

In Eq. (7), $M_{\mathrm{H}_{2} \mathrm{O}}$ is the amount of water vapour, in $\mathrm{kg} / \mathrm{s}$, that is emitted by sweating, natural diffusion of water through the skin and respiration; $S_{\mathrm{b}}$ is the body surface area and $\Delta h$ is the thermal energy associated with the vapour generation, which can be calculated as the difference of the water vapour enthalpy at the ambient temperature and the liquid water enthalpy at the skin temperature:

$\Delta h=h_{\mathrm{v}}\left(t_{\mathrm{a}}\right)-h_{\mathrm{l}}\left(t_{\mathrm{sk}}\right)$

where $h_{\mathrm{v}}=$ specific enthalpy of the water vapour $[\mathrm{J} / \mathrm{kg}] ; t_{\mathrm{a}}=$ air temperature $\left[{ }^{\circ} \mathrm{C}\right] ; h_{1}=$ specific enthalpy of the liquid water $[\mathrm{J} / \mathrm{kg}]$; $t_{\mathrm{sk}}=$ skin temperature $\left[{ }^{\circ} \mathrm{C}\right]$.

Table 2

Carbon dioxide concentration, relative humidity and outside airflow rates.

\begin{tabular}{|c|c|c|c|c|c|c|c|c|c|}
\hline \multirow[t]{2}{*}{ Flight no. } & \multicolumn{3}{|c|}{$\mathrm{CO}_{2}$ concentration [ppmv] } & \multicolumn{3}{|c|}{ Outside airflow rate [L/s person] } & \multicolumn{3}{|c|}{ Relative humidity [\%] } \\
\hline & Min. & Max. & Average & Min. & Max. & Average & Min. & Max. & Average \\
\hline 1 & 867 & 1344 & 1070 & 5.36 & 10.61 & 7.74 & 10.5 & 55.0 & 20.2 \\
\hline 2 & 734 & 1497 & 925 & 4.63 & 14.60 & 10.56 & 8.7 & 51.5 & 20.2 \\
\hline 3 & 957 & 2252 & 1201 & 2.76 & 8.95 & 6.96 & 11.2 & 59.2 & 22.1 \\
\hline 4 & 850 & 2004 & 1238 & 3.18 & 10.99 & 6.86 & 10.7 & 54.0 & 20.7 \\
\hline 5 & 817 & 1837 & 1116 & 3.55 & 11.82 & 7.87 & 11.6 & 54.5 & 21.1 \\
\hline 6 & 824 & 1163 & 960 & 6.60 & 11.64 & 9.12 & 10.3 & 43.8 & 17.9 \\
\hline 7 & 879 & 1581 & 1060 & 4.30 & 10.35 & 8.28 & 13.0 & 44.0 & 22.3 \\
\hline 8 & 1143 & 1496 & 1286 & 4.63 & 6.77 & 5.81 & 17.5 & 33.0 & 22.1 \\
\hline 9 & 961 & 1725 & 1135 & 3.84 & 8.89 & 7.22 & 14.9 & 37.9 & 19.0 \\
\hline 10 & 990 & 1525 & 1247 & 4.51 & 8.47 & 6.20 & 14.4 & 31.1 & 19.2 \\
\hline 11 & 1058 & 1911 & 1258 & 3.37 & 7.62 & 6.24 & 16.1 & 39.0 & 23.2 \\
\hline 12 & 1119 & 1913 & 1401 & 3.37 & 6.99 & 5.32 & 19.1 & 38.5 & 24.7 \\
\hline 13 & 1115 & 2180 & 1449 & 2.87 & 7.03 & 5.18 & 18.6 & 42.3 & 27.0 \\
\hline 14 & 1148 & 2213 & 1345 & 2.82 & 6.73 & 5.87 & 17.5 & 40.0 & 25.9 \\
\hline
\end{tabular}




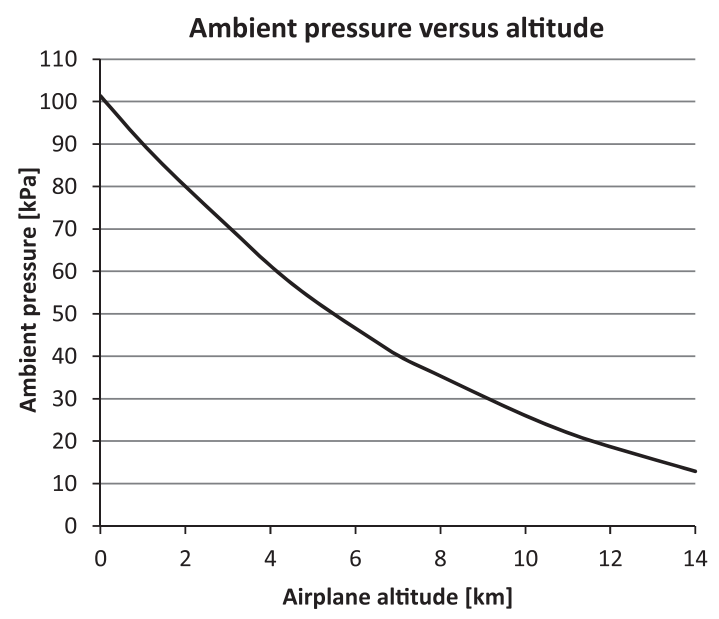

Fig. 4. Variation of ambient pressure with altitude.

To calculate the water vapour enthalpy the following equation can be used [47];

$h_{\mathrm{v}}\left(t_{\mathrm{a}}\right)=\left(2501+1.86 t_{\mathrm{a}}\right) 10^{3}$

Assuming a value of the specific heat of the liquid water equal to $4179 \mathrm{~J} / \mathrm{kg}^{\circ} \mathrm{C}$, enthalpy $h_{1}$ can be evaluated as:

$h_{\mathrm{l}}\left(t_{\mathrm{sk}}\right)=4179\left(t_{\mathrm{sk}}-0.01\right)$

The skin temperature can be calculated by means of the equation proposed by Rohles and Nevins [45]:

$t_{\mathrm{sk}}=37.5-0.0275(M-W)$

Even if the surface temperature of the respiratory duct may be different from the skin temperature, the present study did not consider such a difference in assessing the water emitted by respiration. The body surface area was calculated by means of the relation proposed by DuBois and DuBois [48]:

$S_{\mathrm{b}}=0.202 m^{0.425} l^{0.725}$

where $S_{\mathrm{b}}=$ body surface area $\left[\mathrm{m}^{2}\right] ; m=$ mass $[\mathrm{kg}] ; l=$ height $[\mathrm{m}]$.

In the hypothesis of ideal gas, which is commonly assumed dealing with moist air, water vapour generation rate $\mathrm{N}_{\mathrm{H}_{2} \mathrm{O}}$ in $\mathrm{L} / \mathrm{s}$ per person is given by:

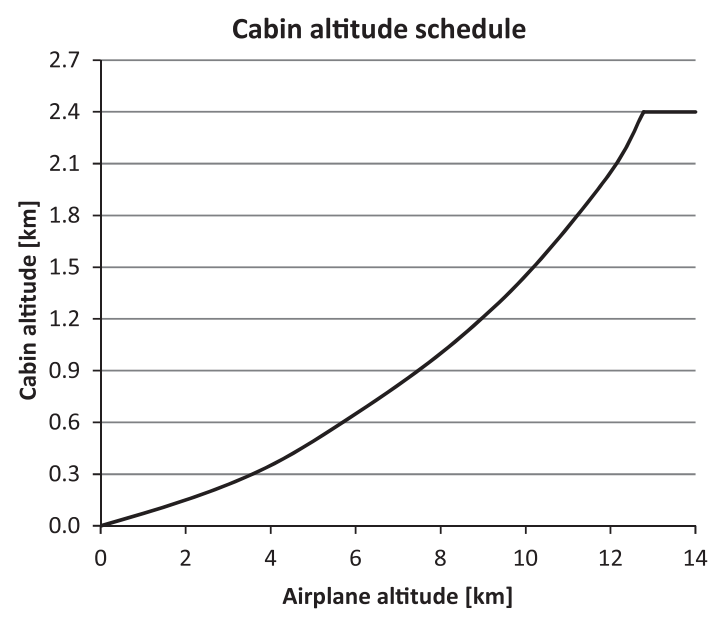

Fig. 5. Cabin altitude schedule.

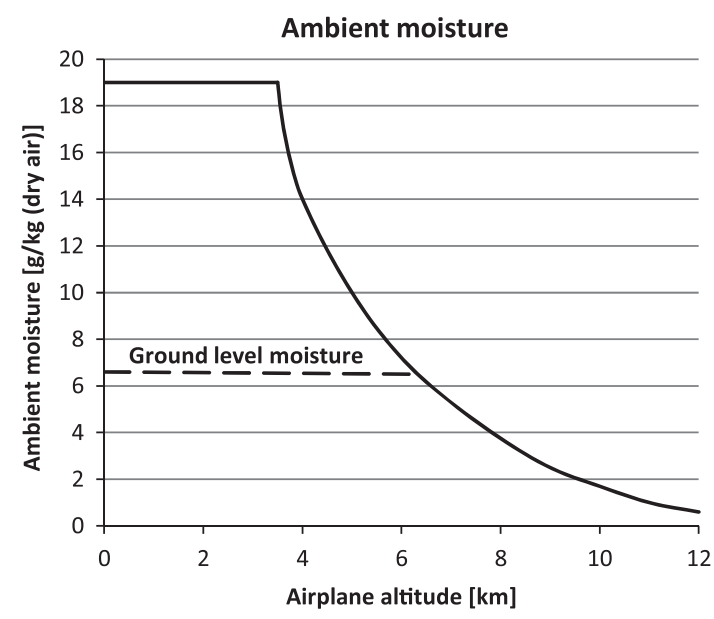

Fig. 6. Variation of ambient moisture with altitude.

$N_{\mathrm{H}_{2} \mathrm{O}}=M_{\mathrm{H}_{2} \mathrm{O}} v_{\mathrm{H}_{2} \mathrm{O}} 10^{3}=M_{\mathrm{H}_{2} \mathrm{O}} \frac{R_{\mathrm{u}} T_{\mathrm{a}}}{n_{\mathrm{H}_{2} \mathrm{O}} p_{\mathrm{a}}} 10^{3}$

where $v_{\mathrm{H}_{2} \mathrm{O}}=$ water vapour specific volume $\left[\mathrm{m}^{3} / \mathrm{kg}\right] ; R_{\mathrm{u}}=$ universal gas constant, $8.31447 \mathrm{~kJ} / \mathrm{kmol} \mathrm{K} ; T_{\mathrm{a}}=$ absolute ambient temperature $[\mathrm{K}] ; n_{\mathrm{H}_{2} \mathrm{O}}=$ water molar mass, $18.02 ; p_{\mathrm{a}}=$ ambient pressure $[\mathrm{Pa}]$.

Water vapour concentration $C_{0, \mathrm{H}_{2} \mathrm{O}}$ in the outside air is given by:

$C_{0, \mathrm{H}_{2} \mathrm{O}}=\frac{V_{\mathrm{w}, 0}}{V_{\mathrm{a}, 0}+V_{\mathrm{w}, 0}} 10^{6}$

where $V_{\mathrm{w}, 0}=$ volume of water vapour in the outside air $\left[\mathrm{m}^{3}\right]$; $V_{\mathrm{a}, 0}=$ volume of dry air in the outside air $\left[\mathrm{m}^{3}\right]$.

If dry air is assumed to be an ideal gas, the volume of water vapour and dry air can be calculated as:

$V_{\mathrm{w}, 0}=m_{\mathrm{w}} v_{\mathrm{H}_{2} \mathrm{O}}=\frac{m_{\mathrm{w}} R_{\mathrm{u}} T_{\mathrm{a}}}{n_{\mathrm{H}_{2} \mathrm{O}} p_{\mathrm{a}}}$

$V_{\mathrm{a}, 0}=m_{\mathrm{a}} v_{\mathrm{a}}=\frac{m_{\mathrm{a}} R_{\mathrm{u}} T_{\mathrm{a}}}{n_{\mathrm{a}} p_{\mathrm{a}}}$

where $m_{\mathrm{w}}=$ mass of water vapour in the outside air $[\mathrm{kg}]$; $m_{\mathrm{a}}=$ mass of dry air in the outside air $[\mathrm{kg}] ; v_{\mathrm{a}}=$ dry air specific volume $\left[\mathrm{kg} / \mathrm{m}^{3}\right] ; n_{\mathrm{a}}=$ air molar mass, 28.96 .

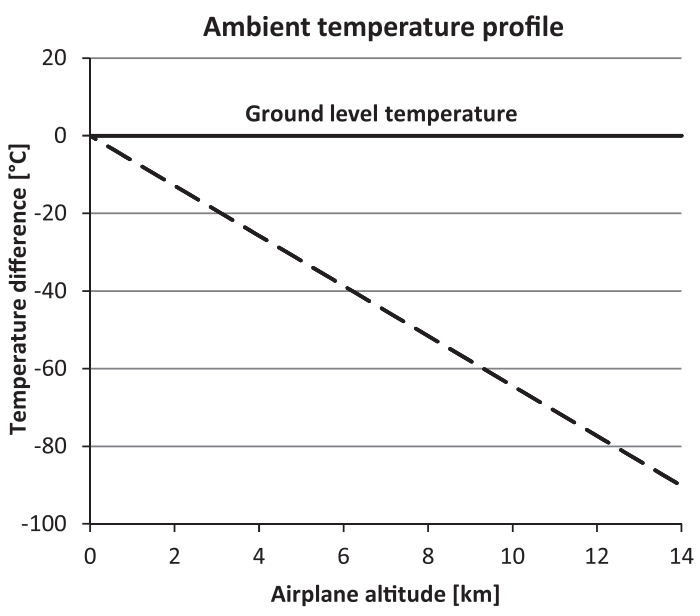

Fig. 7. Ambient temperature profile. 


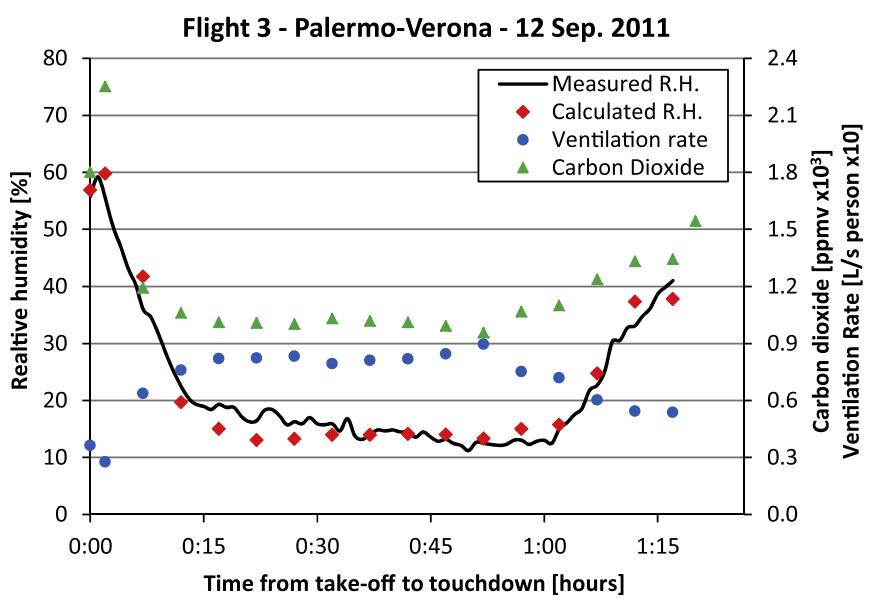

Fig. 8. Calculated and measured relative humidity, ventilation rate and $\mathrm{CO}_{2}$ concentration during flight 3.

Mass of water vapour $m_{\mathrm{w}}$ can be evaluated using the outside air humidity ratio:

$\omega=\frac{m_{\mathrm{w}}}{m_{\mathrm{a}}}$

where $\omega$ is the humidity ratio of the outside air [ $\mathrm{kg}$ water vapour $/ \mathrm{kg}$ dry air].

Using the above equations it is possible to derive the following relation for evaluating the water vapour concentration in the outside air:

$C_{0, \mathrm{H}_{2} \mathrm{O}}=\frac{\frac{m_{\mathrm{w}} R_{\mathrm{u}} T_{\mathrm{a}}}{n_{\mathrm{H}_{2} \mathrm{O}} p_{\mathrm{a}}}}{\frac{m_{\mathrm{a}} R_{\mathrm{u}} T_{\mathrm{a}}}{n_{\mathrm{a}} p_{\mathrm{a}}}+\frac{m_{\mathrm{w}} R_{\mathrm{u}} T_{\mathrm{a}}}{n_{\mathrm{H}_{2} \mathrm{O} p_{\mathrm{a}}}}} 10^{6}=\frac{\frac{\omega}{18.02}}{\frac{1}{28.96}+\frac{\omega}{18.02}} 10^{6}$

To calculate the relative humidity in the cabin that corresponds to water vapour concentration $C_{\mathrm{C}_{\mathrm{H}} \mathrm{O}} \mathrm{O}$, it is necessary to calculate the ambient water vapour pressure $p_{\mathrm{v}}$, which is the pressure of the water vapour if the amount of vapour corresponding to concentration $C_{\mathrm{C}_{1} \mathrm{H}_{2} \mathrm{O}}$ would occupy the entire volume of the cabin without any change in the temperature. Water vapour concentration $C_{\mathrm{C}_{\mathrm{H}} \mathrm{O}} \mathrm{O}$ is:

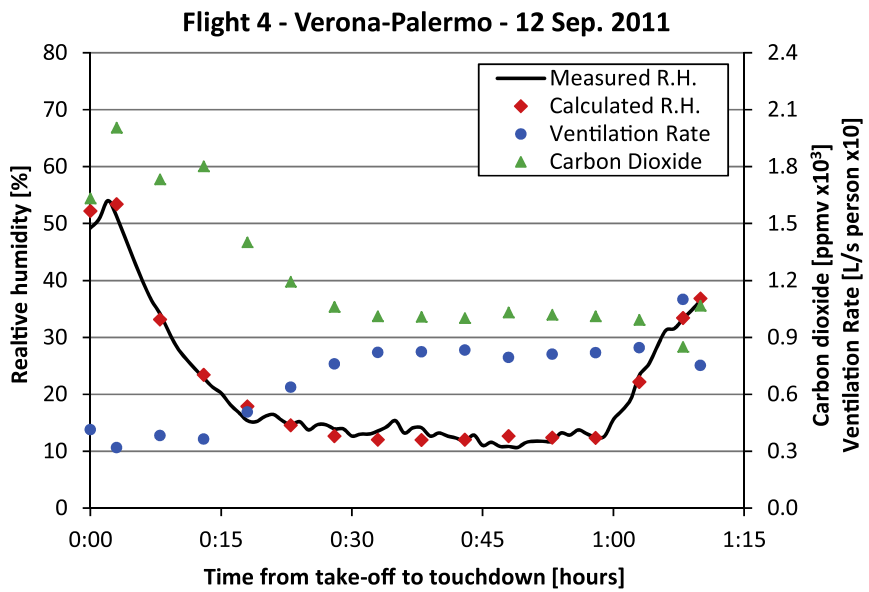

Fig. 9. Calculated and measured relative humidity, ventilation rate and $\mathrm{CO}_{2}$ concentration during flight 4.
Flight 5 - Palermo-Milan - 12 Sep. 2011

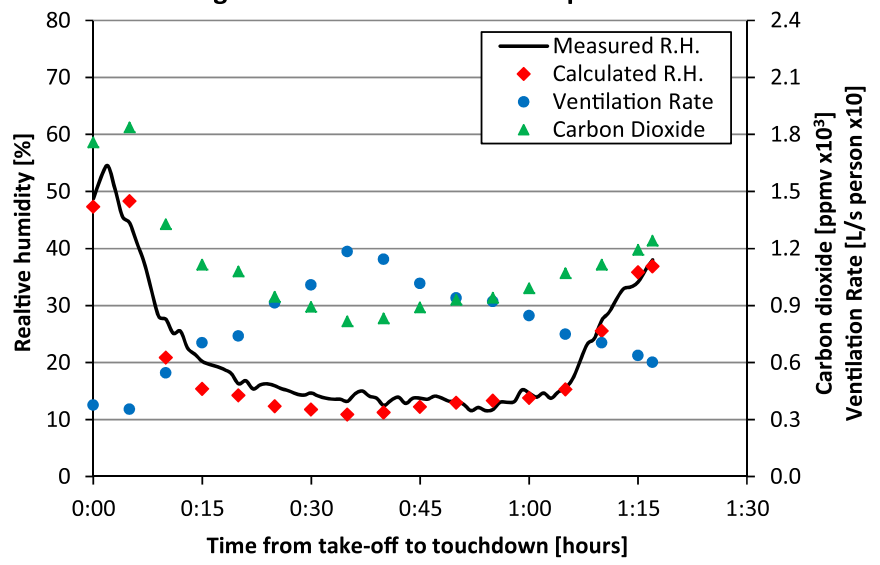

Fig. 10. Calculated and measured relative humidity, ventilation rate and $\mathrm{CO}_{2}$ concentration during flight 5 .

$C_{\mathrm{C}, \mathrm{H}_{2} \mathrm{O}}=\frac{V_{\mathrm{w}, \mathrm{C}}}{V_{\mathrm{a}, \mathrm{C}}+V_{\mathrm{w}, \mathrm{C}}} 10^{6}$

where $V_{\mathrm{w}, \mathrm{C}}=$ volume of water vapour in the cabin $\left[\mathrm{m}^{3}\right]$; $V_{\mathrm{a}, \mathrm{C}}=$ volume of dry air in the cabin $\left[\mathrm{m}^{3}\right]$.

Because, for the properties of the ideal gas, it is:

$p_{\mathrm{a}} V_{\mathrm{w}, \mathrm{C}}=p_{\mathrm{v}}\left(V_{\mathrm{a}, \mathrm{C}}+V_{\mathrm{w}, \mathrm{C}}\right)$

The water vapour pressure can be calculated with the following equation:

$p_{\mathrm{v}}=p_{\mathrm{a}} \frac{V_{\mathrm{w}, \mathrm{C}}}{V_{\mathrm{a}, \mathrm{C}}+V_{\mathrm{w}, \mathrm{C}}}=p_{\mathrm{a}} C_{\mathrm{C}, \mathrm{H}_{2} \mathrm{O}} 10^{6}$

and, in turn, relative humidity $\phi$ is:

$\phi=\frac{p_{\mathrm{v}}}{p_{\mathrm{v}, \mathrm{sat} @ t_{\mathrm{a}}}} 100=\frac{p_{\mathrm{a}} C_{\mathrm{C}, \mathrm{H}_{2} \mathrm{O}}}{p_{\mathrm{v}, \mathrm{sat} @ t_{\mathrm{a}}}} 10^{6} \cdot 100$

in which $p_{\mathrm{v}, \mathrm{sat} @ t_{\mathrm{a}}}$ is the saturation pressure of water vapour at cabin temperature $t_{\mathrm{a}}$.

In order to calculate the relative humidity in the cabin it is necessary to know the flow rate of outside air per person $V_{0}$, temperature $t_{\mathrm{a}}$ and pressure $p_{\mathrm{a}}$ in the cabin, humidity ratio $\omega$ of the

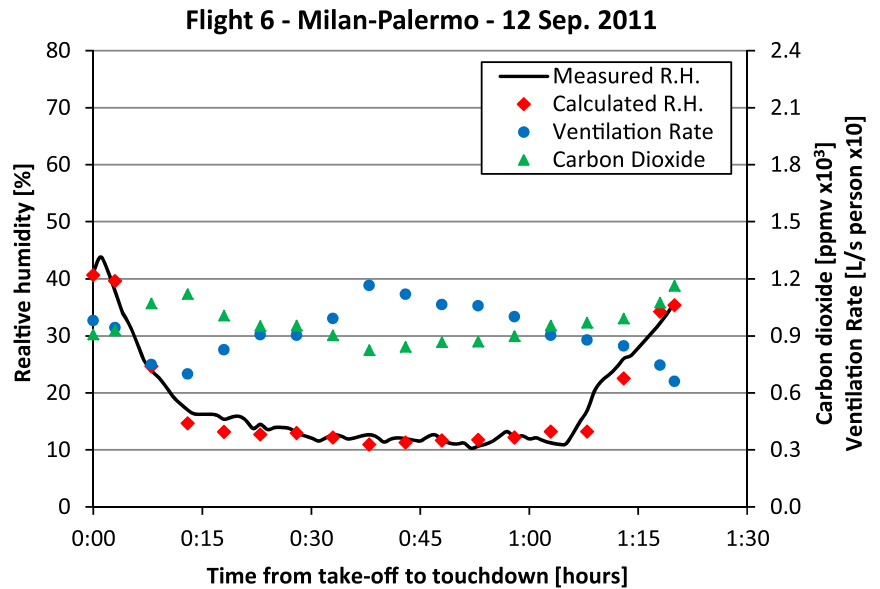

Fig. 11. Calculated and measured relative humidity, ventilation rate and $\mathrm{CO}_{2}$ concentration during flight 6 


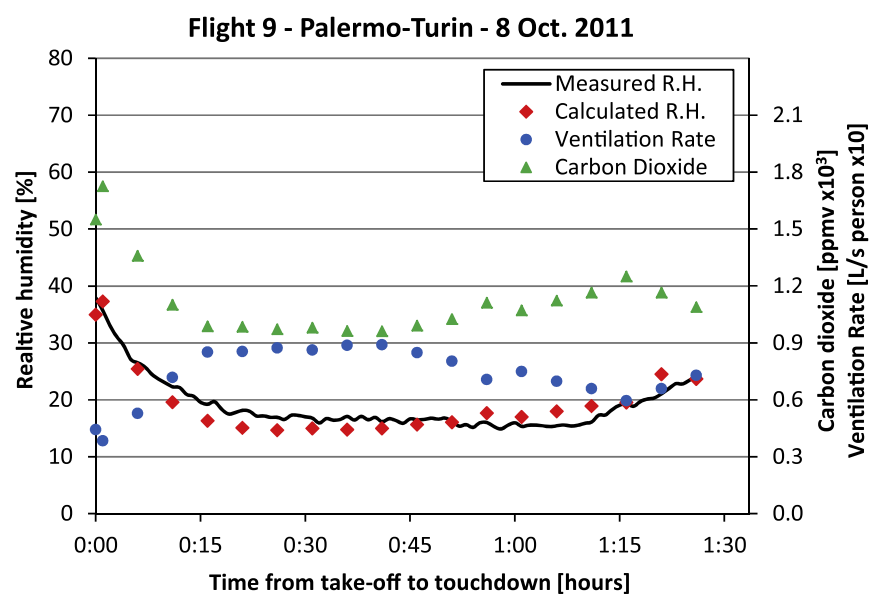

Fig. 12. Calculated and measured relative humidity, ventilation rate and $\mathrm{CO}_{2}$ concentration during flight 9.

outside air, rate of metabolic heat production $M$, mechanical work supplied $W$, mass $m$ and eight $l$ for each one of the crew and passengers. Moreover, to calculate water vapour pressure $p_{\mathrm{v}}$, which is contained in Eqs. (5), (6) and (22), it is necessary to carry out the iterative calculation, which is described in the Appendix.

The outside airflow rate per person was determined by means of Eq. (1) using the measured $\mathrm{CO}_{2}$ concentration; for the temperature in the cabin the measured data were used. The pressure in the cabin is an important parameter that directly affects the calculation of the relative humidity. During high-altitude flights the ECS changes the pressure in order to maintain the cabin pressurization according to the partial pressure of oxygen required for the crew and passengers. To allow the normal physiological functions without supplementary oxygen, the cabin trunk must be pressurized to an equivalent altitude that does not exceed $2400 \mathrm{~m}$. The differential pressure control provides a cabin pressure based on the flight altitude of the aircraft. In order to consider the variation of the cabin pressure, in this paper it was assumed that the ambient pressure and the schedule cabin altitude changed with the aircraft altitude as it is shown in Figs. 4 and 5 [37].

The humidity ratio of the outside air is another relevant parameter of the problem. Actually, the value of the humidity ratio changes with the altitude and with weather conditions. Because it only was possible to get experimental data at ground level, the

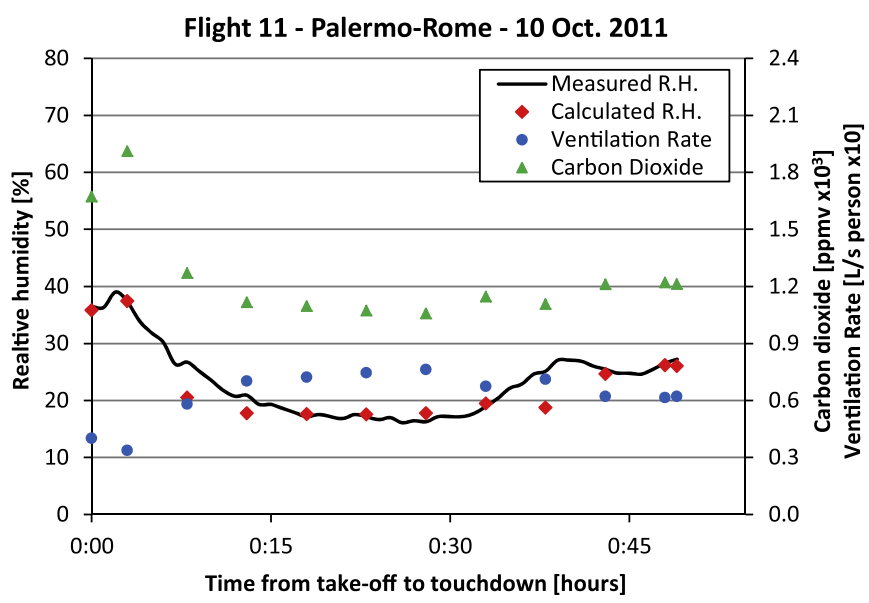

Fig. 14. Calculated and measured relative humidity, ventilation rate and $\mathrm{CO}_{2}$ concentration during flight 11 .

variation of ambient moisture with the altitude proposed by ASHRAE [37], which is shown in Fig. 6, was adopted. Only the values of the diagram of Fig. 6 that are less than the ground level data were used for calculations. Moreover, to avoid using unrealistic values of the humidity ratio, also the effect of the outside air temperature was considered adopting the ambient temperature profile of Fig. 7 [37].

A value of the rate of metabolic heat production equal to 1.15 met was assumed, whereas the rate of the mechanical work supplied was considered negligible. To take into account the presence of both male and female passengers, a value of the body surface area of $1.75 \mathrm{~m}^{2}$ was considered. The saturation pressure of water vapour was calculated using the polynomial equations provided by ASHRAE for saturation pressure over ice and over liquid water in the temperature range of $-100{ }^{\circ} \mathrm{C}-200{ }^{\circ} \mathrm{C}$ [37].

The calculations of the relative humidity were carried out for all flights of Table 1 and the results were compared with the measurements performed from take-off to landing. For the sake of brevity only the results of the most significant flights are depicted in Figs. 8-15.

Observing Figs. 8-15 it is possible to affirm that the used procedure permitted to reach an adequate level of accuracy in calculating the relative humidity in the cabin. The greater differences between calculated and measured data correspond to the lapses of
Flight 10 - Turin-Palermo - 8 Oct. 2011

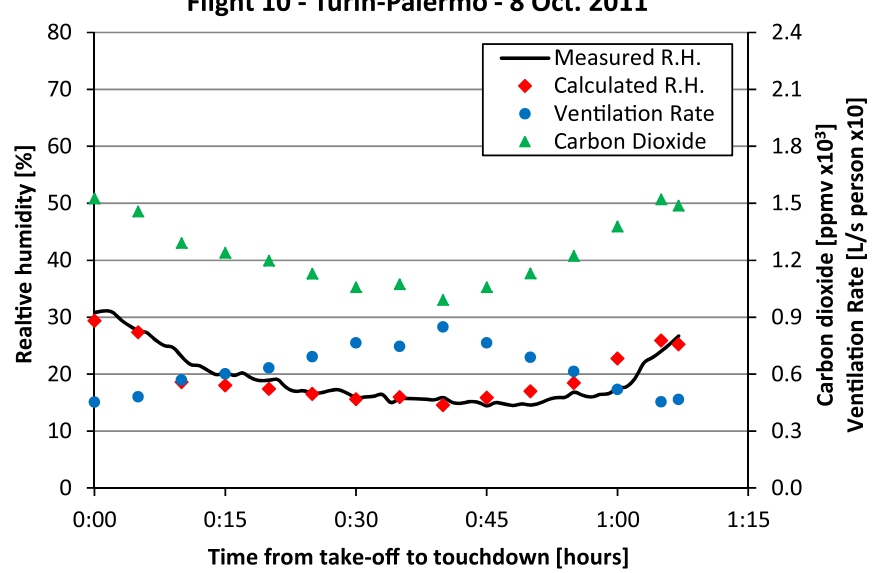

Fig. 13. Calculated and measured relative humidity, ventilation rate and $\mathrm{CO}_{2}$ concentration during flight 10 .

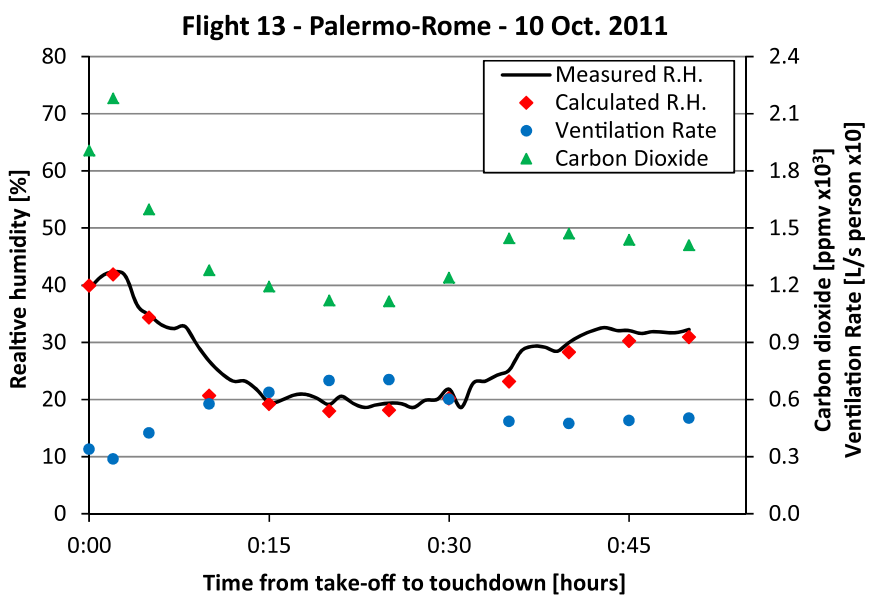

Fig. 15. Calculated and measured relative humidity, ventilation rate and $\mathrm{CO}_{2}$ concentration during flight 13. 
Table 3

Differences between calculated and measured relative humidity.

\begin{tabular}{|c|c|c|c|c|c|c|}
\hline \multirow[t]{2}{*}{ Flight no. } & \multicolumn{3}{|c|}{$\begin{array}{l}\text { Relative humidity absolute } \\
\text { difference [\%] }\end{array}$} & \multicolumn{3}{|c|}{$\begin{array}{l}\text { Relative humidity } \\
\text { difference [\%] }\end{array}$} \\
\hline & Min. & Max. & Average & Min. & Max. & Average \\
\hline 1 & 0.02 & 5.84 & 2.16 & -5.84 & 2.63 & -0.66 \\
\hline 2 & 0.15 & 5.47 & 2.08 & -5.47 & 2.96 & -0.86 \\
\hline 3 & 0.15 & 5.74 & 2.41 & -4.31 & 5.74 & 0.14 \\
\hline 4 & 0.10 & 2.96 & 1.16 & -2.19 & 2.96 & 0.22 \\
\hline 5 & 0.28 & 6.76 & 2.25 & -6.76 & 3.79 & -1.43 \\
\hline 6 & 0.02 & 3.81 & 1.41 & -3.81 & 1.99 & -0.58 \\
\hline 7 & 0.11 & 5.15 & 2.81 & -5.15 & 0.32 & -2.74 \\
\hline 8 & 0.04 & 5.07 & 1.99 & -5.07 & 4.07 & 0.51 \\
\hline 9 & 0.19 & 3.38 & 1.87 & -3.11 & 3.38 & -0.43 \\
\hline 10 & 0.13 & 5.17 & 1.72 & -4.48 & 5.17 & -0.05 \\
\hline 11 & 0.09 & 6.43 & 1.82 & -6.43 & 1.48 & -1.34 \\
\hline 12 & 0.82 & 5.03 & 3.07 & -5.03 & -0.82 & -3.07 \\
\hline 13 & 0.32 & 6.07 & 2.00 & -6.07 & 0.55 & -1.48 \\
\hline 14 & 0.37 & 5.34 & 2.31 & -2.03 & 5.34 & 1.57 \\
\hline
\end{tabular}

time after take-off and before touchdown when the greatest variations in the aircraft altitude are present. Actually, because the calculus is very sensitive to the ambient moisture, which in turn depends on the altitude, the accurate measurements of the aircraft altitude should have been necessary. Unfortunately, the safetyrelated rules obeyed during take-off and touchdown did not permit to ask the crew about the aircraft altitude. For this reason the calculations were performed taking account of the normal maximum rates of change of cabin pressure, which are $150 \mathrm{~m} / \mathrm{min}$ for increasing altitude and $90 \mathrm{~m} / \mathrm{min}$ for decreasing altitude. Table 3 lists some figures of the accuracy achieved in calculating the relative humidity in the cabin.

The average absolute difference between calculated and measured values of the relative humidity ranges from 1.16 to $3.07 \%$, whereas the average difference is included between -3.07 and $1.57 \%$

The absolute maximum differences vary from 2.96 to $6.76 \%$.

\section{Improvement of the relative humidity levels in the cabin}

Because, on the basis of the comparison between measured and calculated data, it can be claimed that the above procedure is able to adequately represent the relationship between relative humidity, $\mathrm{CO}_{2}$ concentration and rate of outside air during flights, such a procedure was used to predict the possibility of increasing the

Flight 3 - Palermo-Verona - 12 Sep. 2011

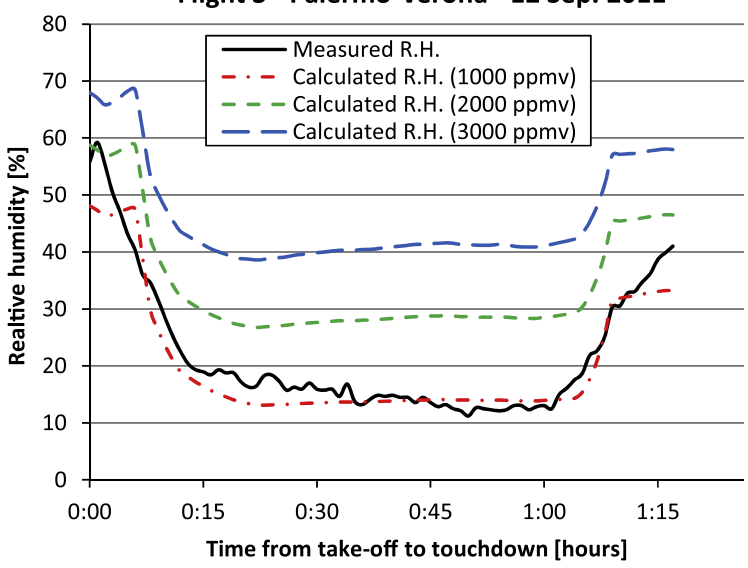

Fig. 16. Measured and simulated relative humidity, for fixed, concentrations of $\mathrm{CO}_{2}$, during flight 3 .

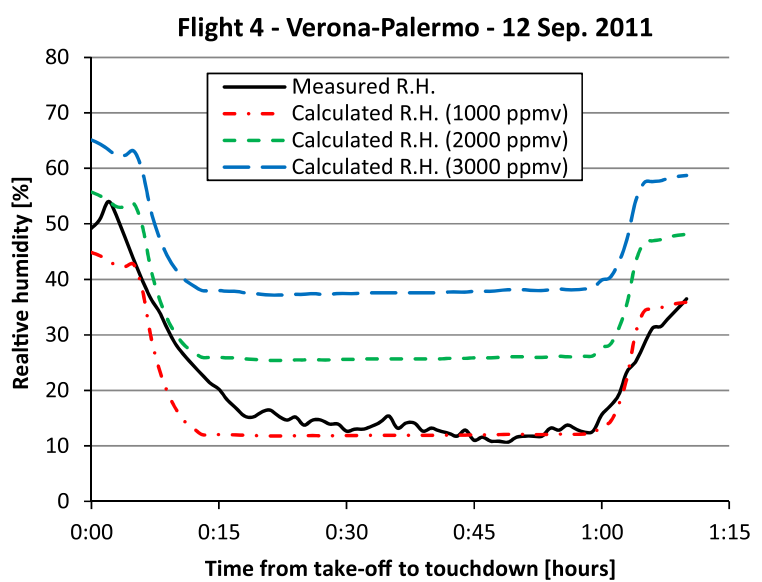

Fig. 17. Measured and simulated relative humidity, for fixed, concentrations of $\mathrm{CO}_{2}$, during flight 4

comfort of the crew and passengers in order to reach a compromise between low levels of $\mathrm{CO}_{2}$ and sufficient values of relative humidity in an aircraft cabin. At first, to reach this purpose, it is necessary to define the limit values of carbon dioxide concentration and the relative humidity in the cabin than can be considered acceptable.

Even if they do not have toxic effects, relatively high values of $\mathrm{CO}_{2}$ concentration are usually correlated to stuffy air for the lack of sufficient ventilation and the increased perception of the odours due to the presence of human bio-effluents. Many Authorities have set the limit of carbon dioxide in workplaces to $3500 \mathrm{ppmv}$ [49] or to 5000 ppmv [50-53]. Carbon dioxide concentrations of 5000 ppmv, sea level equivalent, are also considered the upper limit by the Federal Aviation Administration and the European Joint Aviation Authorities [54,55].

The European Standard EN 4618 [56], which covers the aircraft internal air quality standards, criteria and determination methods, has confirmed the safety limit of 5000 ppmv and has set a comfort limit of $2000 \mathrm{ppvm}$. The comfort limit is assumed as the limit that, if exceeded, would not allow an acceptable cabin environment, which is defined as the one in which a significant majority of the exposed people would not express dissatisfaction with the air quality contaminants and/or environmental criteria. In the EN 4618 Standard it is claimed that such comfort limit was set on the basis of the data collected in the measurements programme carried out in the EC CabinAir Project [57], which consistently indicated an absolute

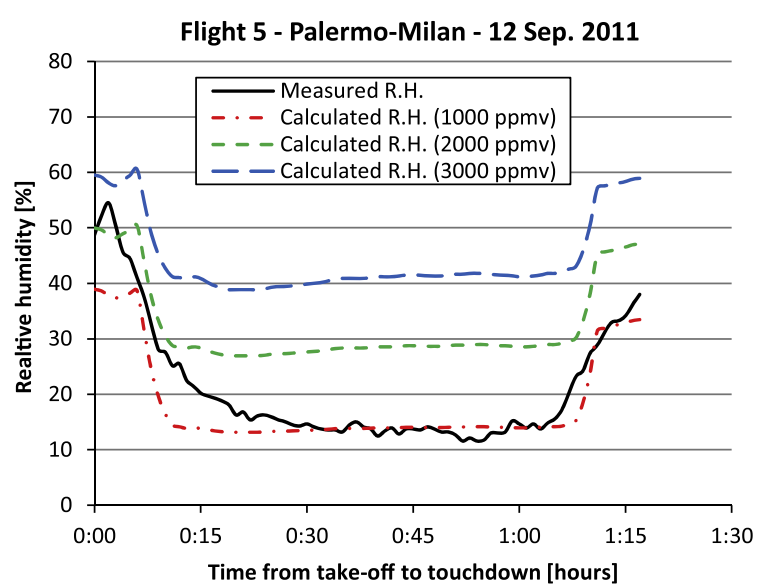

Fig. 18. Measured and simulated relative humidity, for fixed, concentrations of $\mathrm{CO}_{2}$, during flight 5 


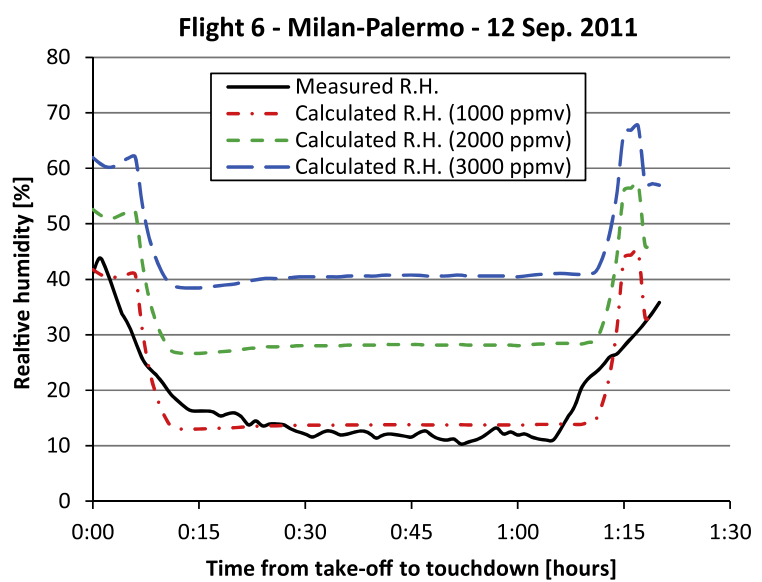

Fig. 19. Measured and simulated relative humidity, for fixed, concentrations of $\mathrm{CO}_{2}$, during flight 6.

carbon dioxide level below 2000 ppmv. Moreover, the results of the analysis of the data collected with the subjective comfort questionnaire further demonstrated that such carbon dioxide levels did not affect comfort.

With the aim of verifying the effect of varying the rate of outside air to increase the level of the relative humidity in the cabin, calculations were performed assuming the ventilation rates necessary to keep the carbon dioxide concentration during flights at a constant value.

Figs. 16-23 show the simulations of the variation of the relative humidity that were carried out assuming the constant $\mathrm{CO}_{2}$ concentrations of 1000, 2000 and 3000 ppmv and the corresponding outside air rates of $8.33,3.19$ and $1.97 \mathrm{~L} / \mathrm{s}$ per person.

Figs. 16-23 highlight the effect of the variation of the rate of outside air that is correlated to the different values of constant $\mathrm{CO}_{2}$ concentrations used in calculations. It easy to see that, with a carbon dioxide concentration of 2000 ppmv the relative humidity in the cabin comes close to $30 \%$ at cruising altitudes, whereas a value of about $40 \%$ is reached if the a $\mathrm{CO}_{2}$ concentration of 3000 ppmv is assumed. For all flights Table 4 lists some figures of the relative humidity in the cabin.

The average relative humidity in the cabin ranges from $29.9 \%$ to $36.0 \%$, for a carbon dioxide concentration of $2000 \mathrm{ppmv}$, and from $42.1 \%$ to $47.7 \%$ with a $\mathrm{CO}_{2}$ concentration of $3000 \mathrm{ppmv}$.

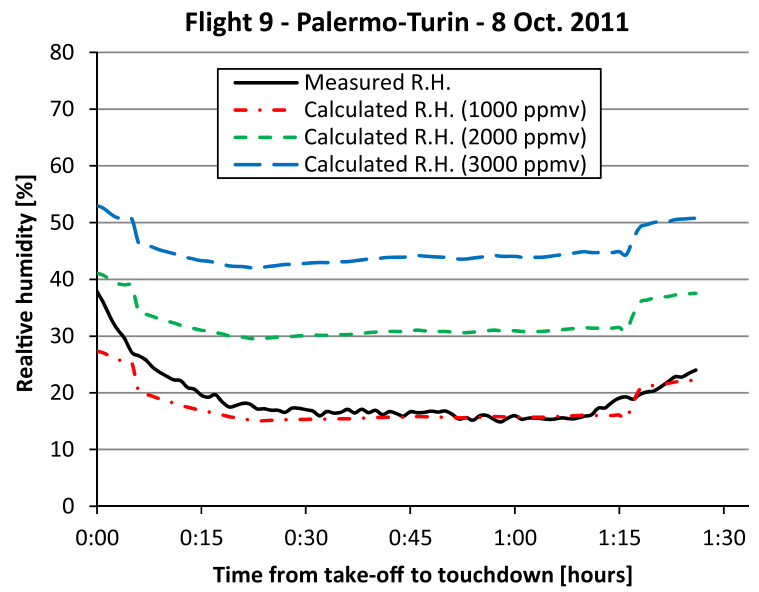

Fig. 20. Variation of measured and simulated relative humidity, for fixed, concentrations of $\mathrm{CO}_{2}$, during flight 9 .

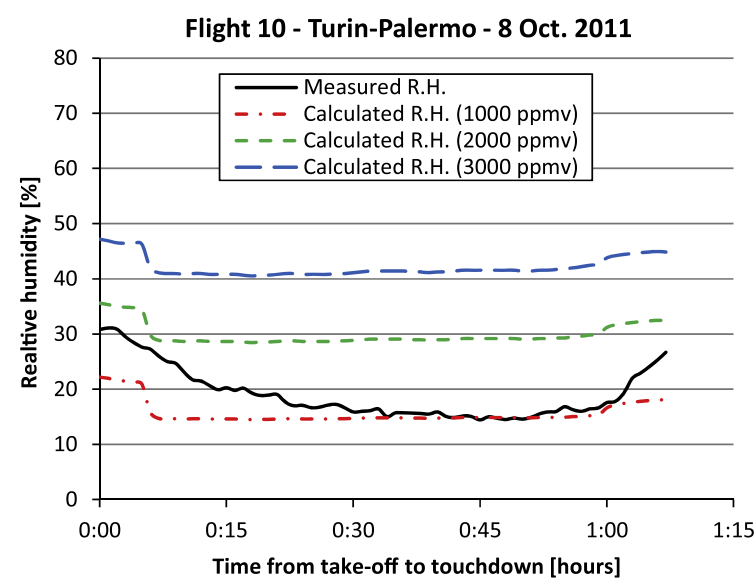

Fig. 21. Measured and simulated relative humidity, for fixed, concentrations of $\mathrm{CO}_{2}$, during flight 10

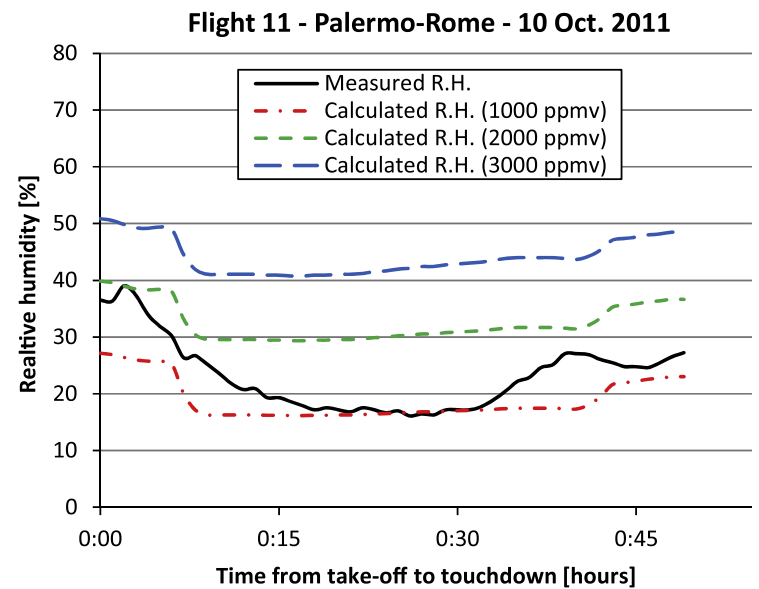

Fig. 22. Measured and simulated relative humidity, for fixed, concentrations of $\mathrm{CO}_{2}$ during flight 11.

Such values of relative humidity are definitely more suited to reduce the discomfort caused by dryness of nose, eyes, throat and skin. On the other hand, the reduction of the ventilation rate may increase the number of persons who may be dissatisfied with the level of body odour in the cabin. The percentage of dissatisfied can be calculated by means of the following equation [58]:

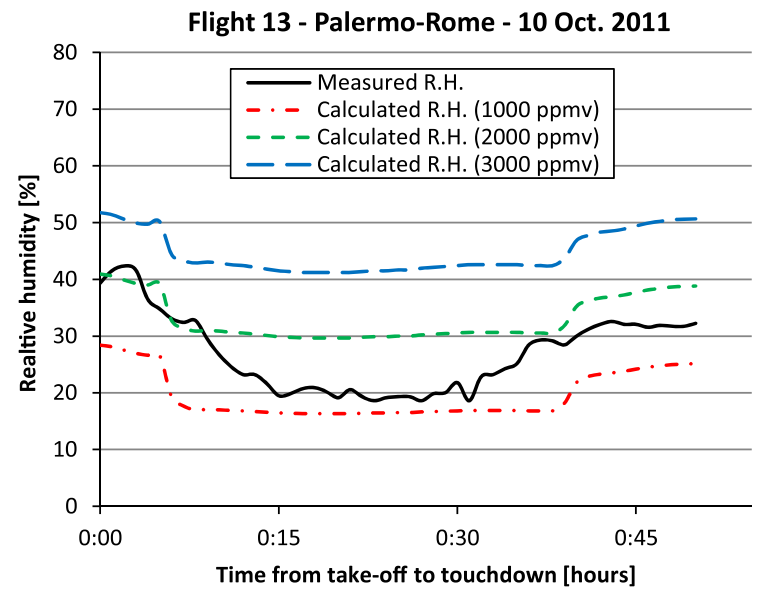

Fig. 23. Measured and simulated relative humidity, for fixed, concentrations of $\mathrm{CO}_{2}$ during flight 13 
Table 4

Figures of the relative humidity calculated for fixed values of $\mathrm{CO}_{2}$ concentration.

\begin{tabular}{|c|c|c|c|c|c|c|c|c|c|}
\hline \multirow[t]{3}{*}{ Flight no. } & \multicolumn{9}{|c|}{ Calculated relative humidity in the cabin [\%] } \\
\hline & \multicolumn{3}{|c|}{$\mathrm{CO}_{2}$ concentration $1000 \mathrm{ppmv}$} & \multicolumn{3}{|c|}{$\mathrm{CO}_{2}$ concentration $2000 \mathrm{ppmv}$} & \multicolumn{3}{|c|}{$\mathrm{CO}_{2}$ concentration $3000 \mathrm{ppmv}$} \\
\hline & Min. & Max. & Average & Min. & Max. & Average & Min. & Max. & Average \\
\hline 1 & 12.5 & 43.9 & 18.7 & 25.6 & 55.1 & 31.8 & 37.0 & 64.9 & 43.1 \\
\hline 2 & 13.4 & 46.4 & 21.9 & 27.3 & 57.5 & 35.6 & 39.4 & 67.1 & 47.5 \\
\hline 3 & 13.1 & 48.1 & 20.4 & 26.7 & 58.8 & 34.1 & 38.6 & 68.5 & 46.0 \\
\hline 4 & 11.8 & 44.9 & 18.1 & 25.4 & 55.7 & 31.4 & 37.2 & 65.1 & 43.0 \\
\hline 5 & 13.2 & 38.9 & 18.4 & 26.9 & 50.4 & 32.4 & 38.9 & 60.6 & 44.5 \\
\hline 6 & 13.0 & 45.1 & 18.7 & 26.7 & 57.2 & 32.4 & 38.4 & 67.6 & 44.3 \\
\hline 7 & 16.3 & 34.1 & 19.7 & 29.6 & 46.5 & 33.2 & 41.1 & 57.2 & 44.8 \\
\hline 8 & 15.9 & 26.8 & 18.4 & 29.5 & 39.6 & 32.3 & 41.4 & 50.7 & 44.3 \\
\hline 9 & 15.0 & 27.4 & 17.4 & 29.5 & 41.1 & 32.2 & 42.0 & 53.0 & 45.0 \\
\hline 10 & 14.5 & 22.2 & 15.7 & 28.4 & 35.6 & 29.9 & 40.5 & 47.2 & 42.1 \\
\hline 11 & 16.2 & 27.1 & 19.0 & 29.4 & 39.9 & 32.5 & 40.8 & 50.9 & 44.2 \\
\hline 12 & 14.1 & 23.0 & 16.9 & 27.9 & 36.3 & 30.7 & 39.8 & 47.8 & 42.6 \\
\hline 13 & 16.3 & 28.4 & 19.6 & 29.7 & 40.9 & 33.1 & 41.2 & 51.8 & 44.7 \\
\hline 14 & 16.6 & 33.0 & 22.5 & 30.1 & 46.4 & 36.0 & 41.8 & 58.0 & 47.7 \\
\hline
\end{tabular}

$\mathrm{PD}=395 e^{-15.15 C_{\mathrm{CO}_{2}}^{-0.25}}$

where $C_{\mathrm{CO}_{2}}$ is the above carbon dioxide concentration outdoors, in ppmv. Actually, Eq. (24), which was defined on the basis of experiments involving office workers and university students with modern habits of personal hygiene $[30,59,60]$, may yields to results not corresponding to the reality dealing with occupants that have different frequency of bathing and societal expectations. Anyway, assuming a value of 380 ppmv and of 2000 ppmv for the concentrations of carbon dioxide in the atmosphere and in the cabin, respectively, Eq. (24) yields a percentage of dissatisfied equal to $36.3 \%$, which permits to claim that a substantial majority of the people exposed would not be expected to express dissatisfaction. With a $\mathrm{CO}_{2}$ concentration in the cabin of 3000 ppmv the percentage of dissatisfied would rise to $47.5 \%$, which may be considered too high. As a conclusion, keeping a carbon dioxide concentration of 2000 ppmv during flight, which is not an issue for the modern ECS technology, can be considered an effective way to reach adequate levels of air quality and hygrometric comfort.

Even if the results of the study seem to be significant, a caveat has to be provided. Table 1 shows that the flight durations ranged from $37 \mathrm{~min}$ to $1 \mathrm{~h}$ and $26 \mathrm{~min}$. Such lapses of time, especially the shorter ones, may be too small to allow the crew and passengers to adapt themselves to the airliner cabin that is an environment quite different from the places, such as the waiting areas of the airport terminal, where people stayed for long before boarding. For this reason, the used steady-state conditions might be considered unrealistic and it would be sensible to adopt a dynamic approach to assess the effects of $\mathrm{CO}_{2}$ and water vapour concentrations especially during the initial part of flights. Unfortunately, because the data describing the variation of the water vapour and $\mathrm{CO}_{2}$ emitted by the human body in transient conditions were not available, the study was carried out assuming the steady-state conditions. Obviously such hypotheses limit the field of validity of the present study to the parts of each flight that are sufficiently far from the take-off. For this reason, as longer the flight durations are, so more reliable the global results should be. In our opinion the conclusions of the present study should be fair valid for long-haul flights, whose duration is greater than $5 \mathrm{~h}$, and transoceanic flights.

\section{Conclusions}

With the aim of assessing the possibility of improving the hygrometric conditions in the aircraft cabins by means of a suitable reduction of the outside airflow rate, a relationship between the relative humidity and carbon dioxide concentration was set. The reliability of the relationship was tested by comparison with the data collected in the passenger cabin of an Airbus A319 during 14 short-haul domestic flights during which the measured values of the relative humidity ranged from $17.9 \%$ to $27.0 \%$.

The relationship was used to predict the possibility of increasing the comfort of the crew and passengers reaching a suitable compromise between low levels of $\mathrm{CO}_{2}$ and sufficient values of relative humidity in the aircraft cabin. The results of calculations showed that, slightly increasing the carbon dioxide concentration up to $2000 \mathrm{ppmv}$, the relative humidity in the cabin comes close to a satisfactory value of $30 \%$ at cruising altitudes, whereas a value of about $40 \%$ can be reached if the a $\mathrm{CO}_{2}$ concentration of $3000 \mathrm{ppmv}$ is assumed as a possible level. If the cabin ventilation rate was controlled by a $\mathrm{CO}_{2}$ detector, the energy cost of the aircraft ECS would decrease and the crew and passengers would feel more comfortable.

\section{Acknowledgments}

The Authors are pleased to thank the WindJet Airline Company and the Commander D. Catalisano for their valuable support, as well as the PHD students M. Ariolo and D. Giurintano who have carried out the measurement campaign onboard the Windjet Aircrafts.

\section{Appendix}

Calculation flow chart for the relative humidity in the cabin. Input data:

$\mathrm{C}_{0, \mathrm{CO}_{2}} \quad \mathrm{CO}_{2}$ concentration in the outside air, from Eq. (19) [ppmv]

$M \quad$ rate of metabolic heat production $\left[\mathrm{W} / \mathrm{m}^{2}\right]$

$p_{\mathrm{a}} \quad$ ambient pressure [Pa]

$S_{\mathrm{b}} \quad$ body surface area $\left[\mathrm{m}^{2}\right]$

$t_{\mathrm{a}}$ ambient temperature $\left[{ }^{\circ} \mathrm{C}\right]$

$T_{\mathrm{a}} \quad$ absolute ambient temperature [K]

$v_{\mathrm{H}_{2} \mathrm{O}} \quad$ water vapour specific volume at $t_{\mathrm{a}}$ and $p_{\mathrm{a}}\left[\mathrm{m}^{3} / \mathrm{kg}\right]$

$V_{0} \quad$ outside airflow rate per person [L/s]

$W \quad$ rate of mechanical work accomplished $\left[\mathrm{W} / \mathrm{m}^{2}\right]$

$\omega \quad$ humidity ratio of the outside air [ $\mathrm{kg}$ water vapour $/ \mathrm{kg}$ dry air]

$p_{\mathrm{v}, \text { sat } @ t_{\mathrm{a}}}$ saturation pressure of water vapour at temperature $t_{\mathrm{a}}$

$N_{\mathrm{H}_{2} \mathrm{O}}=0$ set first attempt value of the water vapour generation rate per person

Beginning of iterative calculation: 


$$
\begin{aligned}
& C_{\mathrm{C}, \mathrm{H}_{2} \mathrm{O}}=\frac{N_{\mathrm{H}_{2} \mathrm{O}}}{V_{0}} 10^{6}+C_{0, \mathrm{H}_{2} \mathrm{O}} \\
& \phi=\frac{p_{\mathrm{a}} C_{\mathrm{C}, \mathrm{H}_{2} \mathrm{O}}}{p_{\mathrm{v}, \mathrm{sat} @ t_{\mathrm{a}}}} 10^{8} \\
& p_{\mathrm{v}}=p_{\mathrm{v}, \mathrm{sat} @ t_{\mathrm{a}}} \frac{\phi}{100} \\
& h_{\mathrm{v}}\left(t_{\mathrm{a}}\right)=\left(2501+1.86 t_{\mathrm{a}}\right) 10^{3} \\
& t_{\mathrm{sk}}=37.5-0.0275(M-W) \\
& h_{\mathrm{l}}\left(t_{\mathrm{sk}}\right)=4179\left(t_{\mathrm{sk}}-0.01\right) \\
& \Delta h=h_{\mathrm{v}}\left(t_{\mathrm{a}}\right)-h_{\mathrm{l}}\left(t_{\mathrm{sk}}\right) \\
& E_{\mathrm{rsw}}=0.42(M-W-58.15) \\
& E_{\mathrm{dif}}=3.05\left[5.73-0.007(M-W)-p_{\mathrm{v}}\right] \\
& E_{\mathrm{res}}=0.0173 M\left(5.87-p_{\mathrm{v}}\right) \\
& E=E_{\mathrm{rsw}}+E_{\mathrm{dif}}+E_{\mathrm{res}} \\
& M_{\mathrm{H}_{2} \mathrm{O}}=\frac{E S_{\mathrm{b}}}{\Delta h} \\
& N_{\mathrm{H}_{2} \mathrm{O}}^{*}=M_{\mathrm{H}_{2} \mathrm{O}} v_{\mathrm{H}_{2} \mathrm{O}} 10^{3}
\end{aligned}
$$$$
\text { IF } N_{\mathrm{H}_{2} \mathrm{O}}^{*}-N_{\mathrm{H}_{2} \mathrm{O}}>\text { Calculation Accuracy. }
$$$$
\text { THEN. }
$$$$
\text { Adequately change the value of } N_{\mathrm{H}_{2} \mathrm{O}} \text { and repeat the iteration }
$$
ELSE

$C_{\mathrm{C}, \mathrm{H}_{2} \mathrm{O}}=\frac{N_{\mathrm{H}_{2} \mathrm{O}}^{*}}{V_{0}} 10^{6}+C_{0, \mathrm{H}_{2} \mathrm{O}}$

$\phi=\frac{p_{\mathrm{a}} C_{\mathrm{C}, \mathrm{H}_{2} \mathrm{O}}}{p_{\mathrm{v}, \mathrm{sat} @ t_{\mathrm{a}}}} 10^{8}$

\section{Nomenclature}

$C_{\mathrm{C}, \mathrm{H}_{2} \mathrm{O}}$ water vapour concentration in the cabin [ppmv]

$\mathrm{C}_{\mathrm{CO}_{2}} \quad \mathrm{CO}_{2}$ concentration above outdoors [ppmv]

$\mathrm{C}_{\mathrm{S}_{2} \mathrm{CO}_{2}} \quad \mathrm{CO}_{2}$ concentration in the cabin [ppmv]

$\mathrm{C}_{0, \mathrm{CO}_{2}} \quad \mathrm{CO}_{2}$ concentration in the outside air [ppmv]

$\mathrm{C}_{0, \mathrm{H}_{2} \mathrm{O}}$ water vapour concentration in the outside air [ppmv]

$E$ rate of evaporative heat loss of the body $\left[\mathrm{W} / \mathrm{m}^{2}\right]$

$E_{\text {dif }} \quad$ rate of heat loss due to water diffusion through the skin $\left[\mathrm{W} / \mathrm{m}^{2}\right]$

$E_{\text {res }} \quad$ rate of heat loss due to respiration $\left[\mathrm{W} / \mathrm{m}^{2}\right]$

$E_{\mathrm{rsw}} \quad$ rate of heat loss due to sweating $\left[\mathrm{W} / \mathrm{m}^{2}\right]$

$h_{1} \quad$ specific enthalpy of the liquid water $[\mathrm{J} / \mathrm{kg}]$

$h_{\mathrm{v}} \quad$ specific enthalpy of the water vapour $[\mathrm{J} / \mathrm{kg}]$

$l \quad$ body height [m]

$M \quad$ rate of metabolic heat production $\left[\mathrm{W} / \mathrm{m}^{2}\right]$

$M_{\mathrm{H}_{2} \mathrm{O}} \quad$ water vapour emitted by the body $[\mathrm{kg} / \mathrm{s}]$

$m \quad$ body mass [kg]

$m_{\mathrm{a}} \quad$ mass of dry air in the outside air [kg]

$m_{\mathrm{w}} \quad$ mass of water vapour in the outside air[ $\left.\mathrm{kg}\right]$

$N_{\mathrm{CO}_{2}} \quad \mathrm{CO}_{2}$ generation rate per person [L/s]

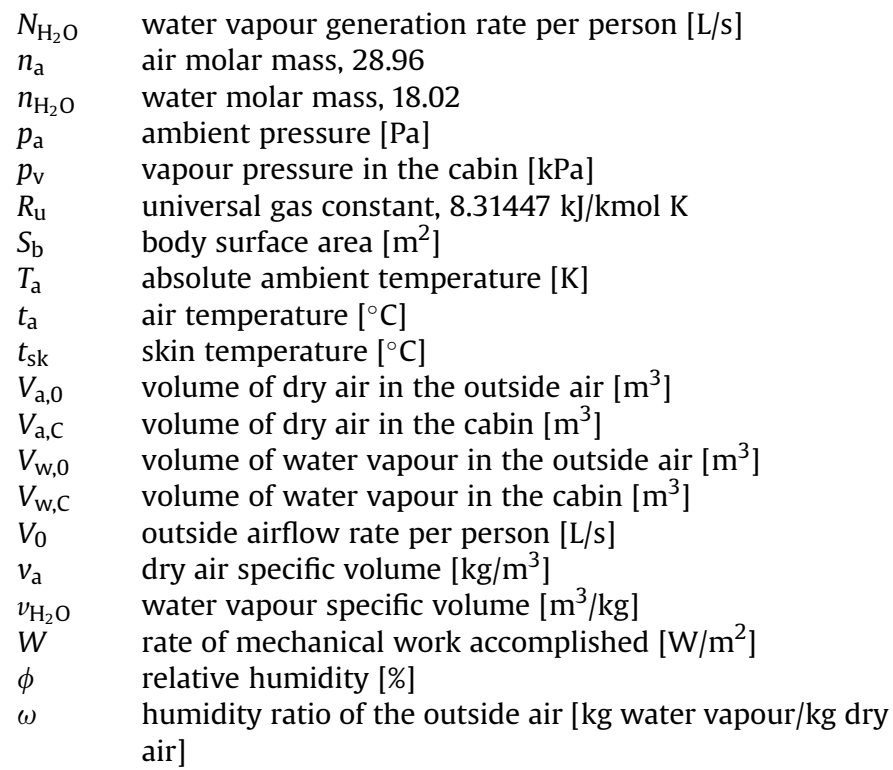

\section{References}

[1] Dechow M, Sohn H, Steinhanses J. Concentrations of selected contaminants in cabin air of airbus aircrafts. Chemosphere 1997;35(1/2):21-31.

[2] Lee S, Poon C, Li X, Luk F. Indoor air quality investigation on commercial aircraft. Indoor Air 1999;9:180-7.

[3] Haghighat F, Allard F, Megri AC, Blondeau P, Shimotakahara R. Measurement of thermal comfort and indoor air quality aboard 43 flights on commercial airlines. Indoor Built Environment 1999;8:58-66.

[4] Wang A, Zhang Y, Sun Y, Wang X. Experimental study of ventilation effectiveness and air velocity distribution in an aircraft cabin mockup. Building and Environment 2008;43:337-43.

[5] Kühn M, Bosbach J, Wagner C. Experimental parametric study of forced and mixed convection in a passenger aircraft cabin mock-up. Building and Environment 2009;44:961-70.

[6] Chen Q Jones BW, Loo SM, Nazaroff WW, Overfelt RA, Spengler JD, et al Report to the FAA on the Airliner Cabin Environment. Report No. RITE-ACERCoE-2010-1. National Air Transportation Center of Excellence for Research in the Intermodal Transport Environment (RITE) - Airliner Cabin Environmental Research (ACER) Program; 2010.

[7] Spengler JD, Vallarino J, McNeely E, Estephan H, Sumner AL. In-flight/onboard monitoring: ACER's component for ASHRAE 1262, Part 2. Report No. RITEACER-CoE-2012-6. National Air Transportation Center of Excellence for Research in the Intermodal Transport Environment (RITE) - Airliner Cabin Environmental Research (ACER) Program; 2012.

[8] Gladyszewska-Fiedoruk K. Indoor air quality in the cabin of an airliner. Journal of Air Transport Management 2012;20:28-30.

[9] Chen Q, McDevitt JJ, Gupta JK, Jones BW, Mazumdar S, Poussou SB, et al. Infectious disease transmission in airliner cabins. Report No. RITE-ACER-CoE2012-01. National Air Transportation Center of Excellence for Research in the Intermodal Transport Environment (RITE) - Airliner Cabin Environmenta Research (ACER) Program; 2012.

[10] Chen Q Zhang Z. Prediction of particle transport in enclosed environment. China Particuology 2005;3(6):364-72.

[11] Zhang Z, Chen Q. Experimental measurements and numerical simulations of particle transport and distribution in ventilated rooms. Atmospheric Environment 2006;40:3396-408.

[12] Zhang Z, Chen Q. Comparison of the Eulerian and Lagrangian methods for predicting particle transport in enclosed spaces. Atmospheric Environment 2007;41:5236-48.

[13] Zhang TF, Chen Q. Identification of contaminant sources in enclosed environments by inverse CFD modeling. Indoor Air 2007;17:167-77.

[14] Mazumdar S, Chen Q. A one-dimensional analytical model for airborne contaminant transport in airliner cabins. Indoor Air 2009;19:3-13.

[15] Zhang T, Chen Q. Novel air distribution systems for commercial aircraft cabins. Building and Environment 2007;42:1675-84.

[16] Poussou SB, Mazumdar S, Plesniak MW, Sojka PE, Chen Q. Flow and contaminant transport in an airliner cabin induced by a moving body: model experiments and CFD predictions. Atmospheric Environment 2010;44:2830-9.

[17] Mazumdar S, Poussou SB, Lin CH, Isukapalli SS, Plesniak MW, Chen O. Impact of scaling and body movement on contaminant transport in airliner cabins. Atmospheric Environment 2011;45:6019-28.

[18] Gupta JK, Lin $\mathrm{CH}$, Chen $\mathrm{O}$. Inhalation of expiratory droplets in aircraft cabins. Indoor Air 2011;21(4):341-50.

[19] Gupta JK, Lin CH, Chen Q. Transport of expiratory droplets in an aircraft cabin. Indoor Air 2011;21(1):3-11. 
[20] Gupta JK, Lin $\mathrm{CH}$, Chen Q. Risk assessment for airborne infectious diseases in aircraft cabins. Indoor Air 2012;22(5):388-95.

[21] Rankin WL, Space DR, Nagda NL. Passenger comfort and the effect of air quality. In: Nagda NL, editor. Air quality and comfort in airliner cabins. Conshohocken, PA: American Society for Testing and Materials (ASTM); 2000. p. 269-89.

[22] Lee SC, Poon CS, Li D, Luk F, Chang M. Questionnaire survey to evaluate the health and comfort of cabin crew. In: Nagda NL, editor. Air quality and comfort in airliner cabins. Conshohocken, PA: American Society for Testing and Materials (ASTM); 2000. p. 259-66.

[23] Lindgren T, Norbäck D, Andersson K, Dammstrom BG. Cabin environment and perception of cabin air quality among commercial aircrew. Aviation Space and Environmental Medicine 2000;71(8):774-82.

[24] Lindgren T, Norbäck D. Health and perception of cabin air quality among Swedish commercial airline crew. Indoor Air 2005;15(s10):65-72.

[25] Nagda NL, Hodgson M. Low relative humidity and aircraft cabin air quality Indoor Air 2001;11(3):200-14.

[26] Lindgren T, Norbäck D, Wieslander G. Perception of cabin air quality in airline crew related to air humidification, on Intercontinental flights. Indoor Air 2007;17(3):204-10.

[27] Strøm-Tejsen P, Wyon DP, Lagercrantz L, Fang L. Occupant evaluation of 7-hour exposures in a simulated aircraft cabin - Part 1: Optimum balance between fresh air and supply and humidity. Indoor Air 2005:40-5.

[28] Grün G, Trimmel M, Holm A. Low humidity in the aircraft cabin environment and its impact on well-being - results from laboratory study. Building and Environment 2012;47:23-31.

[29] ASHRAE Standard 62.1-2007. Ventilation for acceptable indoor air quality 2007.

[30] Berg-Munch B, Clausen G, Fanger PO. Ventilation requirements for the control of body odour in spaces occupied by women. Environment International 1986;12:195-9.

[31] Cain WS, Leaderer BP, Isseroff R, Berglund LG, Huey RJ, Lipsitt ED, et al. Ventilation requirements in buildings - I. Control of occupancy odor and tobacco smoke odor. Atmospheric Environment 1983;17(6):1183-97.

[32] Fanger PO, Berg-Munch B. Ventilation and body odor. In: Proceedings of Engineering Foundation Conference on Management of atmospheres in tightly enclosed spaces. Atlanta: ASHRAE; 1983. p. 45-50.

[33] Catalisano D, Giaconia C, Grillo C, Montano F. An experimental investigation on air quality inside WindJet aircraft. In: 4th International Conference on Applied human factors and Ergonomics 2012 (AHFE 2012) San Francisco, California, USA, July 21-25 2012.

[34] Zhang T, Chen $\mathrm{Q}$, Lin $\mathrm{CH}$. Optimal sensor placement for airborne contaminant detection in an aircraft cabin. HVAC\&R Research 2007;13(5):683-96.

[35] Mazumdar S, Chen Q. Influence of cabin conditions on placement and response of contaminant detection sensors in a commercial aircraft. Journal of Environmental Monitoring 2008;10:71-81.

[36] Loo SM, Jones B, Kiepert J, Pook M, Anderson M. Bleed-air sensing: wireless sensor networks in mock-up cabin. Report No. RITE-ACER-CoE-2012-4. National Air Transportation Center of Excellence for Research in the Intermodal Transport Environment (RITE), Airliner Cabin Environment Research Program; 2012.

[37] ASHRAE. Hvac application 2007.

[38] Machida T, Kita K, Kondo Y, Blake D, Kawakami S, Inoue G, et al. Vertical and meridional distributions of the atmospheric $\mathrm{CO} 2$ mixing ratio between northern midlatitudes and southern subtropics. Journal of Geophysical Research 2003;108(d3)
[39] Sawa Y, Matsueda H, Makino Y, Inoue HY, Murayama S, Hirota M, et al. Aircraft Observation of $\mathrm{CO}_{2}, \mathrm{CO}, \mathrm{O}_{3}$ and $\mathrm{H}_{2}$ over the North Pacific during the PACE-7 Campaign. Tellus 2004;56B:2-20.

[40] Foucher PY, Chédin A, Armante R, Boone C, Crevoisier C, Bernath P. Carbon dioxide atmospheric vertical profiles retrieved from space observation using ACE-FTS solar occultation instrument. Atmospheric Chemistry and Physics 2011;11:2455-70.

[41] Tuzson B, Henne S, Brunner D, Steinbacher M, Mohn J, Buchmann B, et al. continuous isotopic composition measurements of tropospheric $\mathrm{CO}_{2}$ at Jungfraujoch (3580 $\mathrm{m}$ a.s.l.), Switzerland: real-time observation of regional pollution events. Atmospheric Chemistry and Physics 2011;11:1685-96.

[42] Hocking MB. Passenger aircraft cabin air quality: trends, effects, societal costs, proposals. Chemosphere 2000;41:603-15.

[43] Fanger PO. Calculation of thermal comfort: Introduction of a basic comfort equation. ASHRAE Transactions 196; 773(2): III.4.1.

[44] Fanger PO. Thermal comfort analysis and applications in environmental engineering. New York: McGraw-Hill; 1970.

[45] Rohles Jr FH, Nevins RG. The nature of thermal comfort for sedentary man. ASHRAE Transactions 1971;77(1):239.

[46] Fanger PO. Thermal comfort. Malabar, FL: Robert E. Krieger; 1982.

[47] ASHRAE. Fundamentals 2009.

[48] DuBois D, DuBois F. A formula to estimate approximate surface area, if height and weight are known. Archives of Internal Medicine 1916;17:863-71.

[49] Exposure guidelines for residential indoor air quality: a report of the FederalProvincial Advisory Committee on Environmental and Occupational Health. Health Canada; 1995.

[50] Code of federal regulations, Title 29, part 1910-1000. U.S. Department of labour, occupational safety and health administration.

[51] Maximum concentrations at the workplace and biological tolerance values for working materials. Commission for the Investigation of Health Hazard of Chemical Compounds in the Work Area, Federal Republic of Germany; 2000.

[52] NIOSH pocket guide to chemical hazards (NPG). National Institute for Occupational Safety and Health; 2004

[53] Threshold limit values for chemical substances and physical agents and biological exposure indices. In: American Conference of Governmental Industrial Hygienists 2001.

[54] Federal Aviation Administration. FAR 25. Airworthiness standards - transport category.

[55] European Joint Aviation Authorities. JAR 25. Large Aeroplanes.

[56] Aerospace series - aircraft internal air quality standards, criteria and determination methods.

[57] Ross D, Crump D, Hunter C, Perera E, Sheridan A. Client report: extending cabin air measurements to include older aircraft types utilised in high volume short haul operation. BRE Environment; 2003.

[58] ECA, European Collaborative Action, Indoor air quality and its impact on man Guideline for ventilation requirements in building. Report No. 11, EUR1449EN.

[59] Fanger PO, Bergh-Munch B. Ventilation requirements for the control of body odour. In: Proceedings of an Engineering Foundation Conference on Management of atmospheres in tightly enclosed spaces. ASHRAE; 1983. p. 45-60.

[60] Rasmussen C, Clausen GH, Bergh-Munch B, Fanger PO. The influence of human activity on ventilation requirements for the control of body odour. In: Proceedings of CLIMA 2000 World Congress on heating, ventilating and airconditioning, Copenhagen 1985;4. p. 357-63. 